\title{
Surfactant Based Enhanced Oil Recovery and Foam Mobility Control
}

\author{
$1^{\text {st }}$ Semi-Annual Technical Report
}

Reporting Period Start Date: July 2003

Reporting Period End Date: December 2003

\author{
Principal Authors: \\ George J. Hirasaki, Rice University \\ Clarence A. Miller, Rice University \\ Gary A. Pope, The University of Texas \\ Richard E. Jackson, INTERA \\ Date Report was Issued: February 2004 \\ DE-FC26-03NT15406 \\ Rice University \\ Department of Chemical Engineering, MS-362 \\ 6100 Main Street \\ Houston, TX 77005-1892 \\ The University of Texas \\ Department of Petroleum Engineering \\ P.O. Box 7726 \\ Austin, TX 78713-7726 \\ INTERA, Inc. \\ 9111A Research Blvd. \\ Austin, TX 78758
}




\section{DISCLAIMER}

This report was prepared as an account of work sponsored by an agency of the United States Government. Neither the United States Government nor any agency thereof, nor any of their employees, make any warranty, expressed or implied, or assumes any legal liability or responsibility for the accuracy, completeness, or usefulness of any information, apparatus, product, or process disclosed, or represents that its use would not infringe privately owned rights. References herein to any specific commercial product, process, or service by trade name, trademark, manufacturer, or otherwise does not necessarily constitute or imply its endorsement, recommendation, or favoring by the United States Government or any agency thereof. The views and opinions of authors expressed herein do not necessarily state or reflect those of the United States Government or and agency thereof. 


\begin{abstract}
Surfactant flooding has the potential to significantly increase recovery over that of conventional waterflooding. The availability of a large number of surfactant structures makes it possible to conduct a systematic study of the relation between surfactant structure and its efficacy for oil recovery. Also, the addition of an alkali such as sodium carbonate makes possible in situ generation of surfactant and significant reduction of surfactant adsorption. In addition to reduction of interfacial tension to ultra-low values, surfactants and alkali can be designed to alter wettability to enhance oil recovery.
\end{abstract}

An alkaline surfactant process is designed to enhance spontaneous imbibition in fractured, oil-wet, carbonate formations. It is able to recover oil from dolomite core samples from which there was no oil recovery when placed in formation brine. 


\section{TABLE OF CONTENTS}

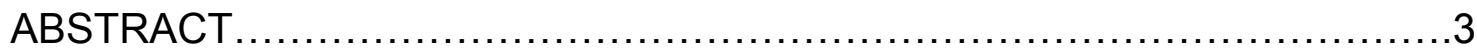

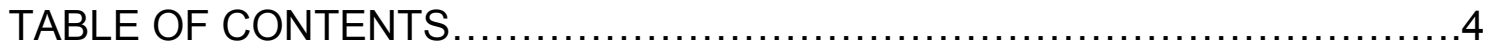

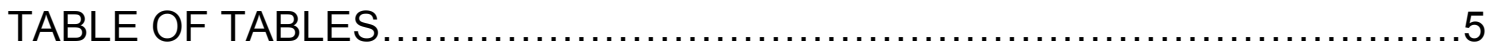

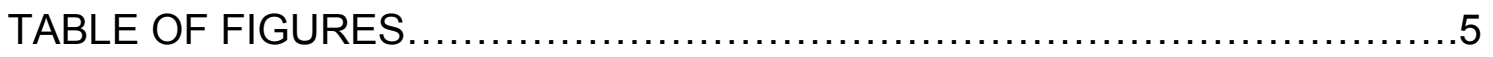

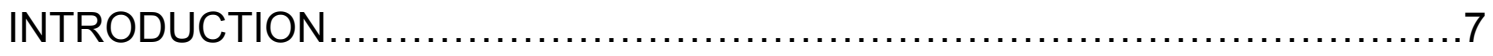

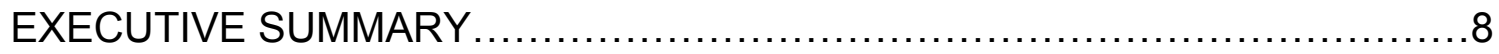

Subtask 1.1 Identifying and synthesizing improved, cost-effective surfactants....9

Subtask 1.2 Surfactant tailoring for crude oils and phase behavior..............14

Task 2 Phase behavior, adsorption, and composition changes during

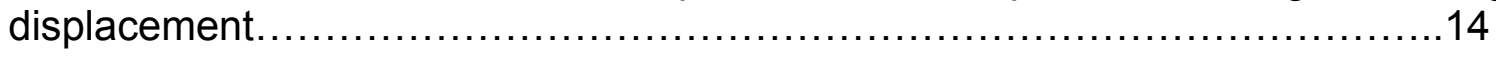

Surface Chemistry of Oil Recovery From Fractured, Oil-Wet, Carbonate

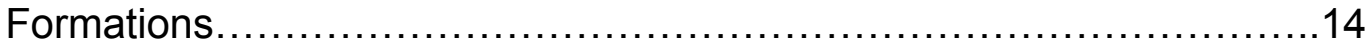

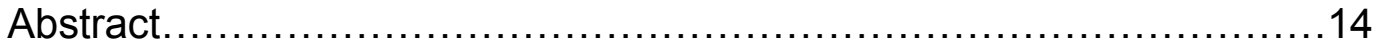

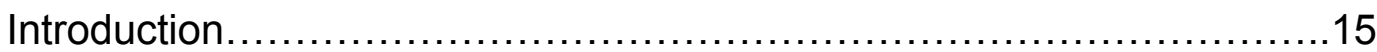

Crude Oil Samples...................................................... 16

Formation Wettability ................................................ 17

Spontaneous Imbibition.............................................. 19

Surfactant Formulations ................................................. 20

Mixing with formation brine ..............................................

Alkali consumption and surfactant adsorption..........................22

Oil recovery by spontaneous imbibition.................................23

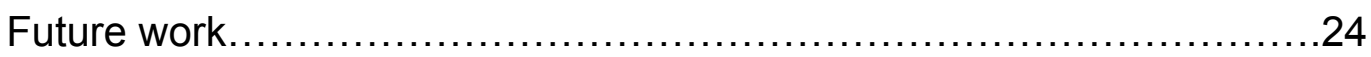

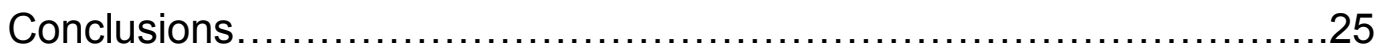

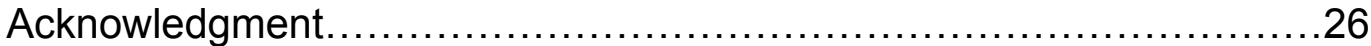

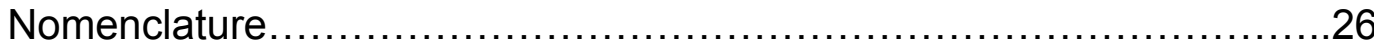

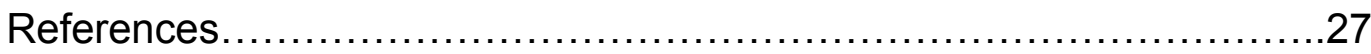




\section{TABLE OF TABLES}

Table 1.1. Candidate Surfactants: Description \& Tradenames.................10

Table 1.2: Phase Behavior Experiments with Decane, 1.5\% Surfactant and 0.05

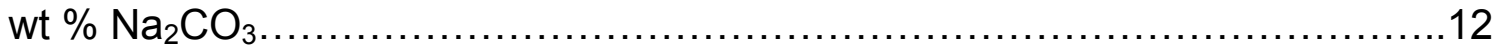

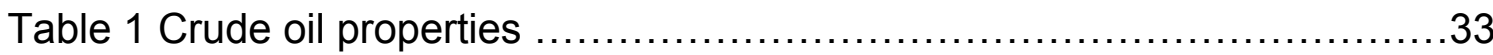

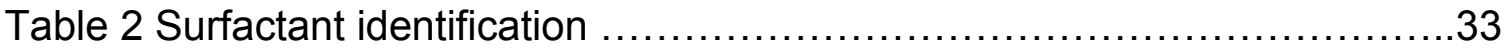

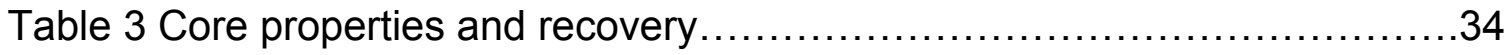

Table 4 Formation brine composition...........................................

\section{TABLE OF FIGURES}

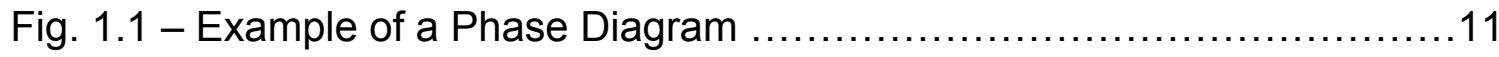

Fig. 1.2 Viscosity vs. Shear Rate for Middle Phase Microemulsion in DOE 47 (Harcros TDA-4PO-sulfate sodium salt) with Decane at $60{ }^{\circ} \mathrm{C} \ldots \ldots \ldots \ldots \ldots \ldots . \ldots 13$

Fig. 1.3 Viscosity vs. Shear Rate for Middle Phase Microemulsion in DOE 52 (Harcros TDA-1EO-4PO-sulfate sodium salt) with Decane at $60{ }^{\circ} \mathrm{C} \ldots \ldots \ldots \ldots . .13$

Fig. 1 The height of the retained oil in oil-wet matrix pores is a function of the pore radius, interfacial tension, and contact angle.............................. 36

Fig. 2 Oil is trapped by surface trapping in oil-wet and small pores of oil-wet systems. 36

Fig. 3 Spontaneous imbibition of surfactant solution from the fracture system into the matrix occurs to replace the oil that flows out of the matrix by buoyancy.....37

Fig. 4 Crude oil/brine IFT is an indication of whether of not the crude oil is contaminated with surface-active materials. 37

Fig. 5 Water advancing contact angles of MY1 and MY3 crude oils on calcite and glass with 5-10 minutes aging time. 38

Fig. 6 Water advancing contact angle of MY3 crude oil in $0.1 \mathrm{M} \mathrm{NaCl}$ brine after aging for 24 hours either at room temperature or $80^{\circ} \mathrm{C}$. .38

Fig. 7 Zeta potential of MY1 crude oil/brine and calcite/brine interfaces in $0.02 \mathrm{M}$ $\mathrm{NaCl}$ as a function of $\mathrm{pH}$ without and with added $\mathrm{Na}_{2} \mathrm{CO}_{3} / \mathrm{NaHCO}_{3}$ and $\mathrm{pH}$ adjusted with $\mathrm{HCl}$. 39

Fig. 8 Wettability alteration of calcite plate aged at room temperature with $0.05 \%$ CS-330 / $0.5 \mathrm{M} \mathrm{Na}_{2} \mathrm{CO}_{3}$

Fig. 9 Wettability alteration of calcite plate aged at $80{ }^{\circ} \mathrm{C}$ with $0.05 \%$ CS-330 / 0.5 $\mathrm{M} \mathrm{Na}_{2} \mathrm{CO}_{3}$. (Two different drops show different wettability.).

Fig. 10 Family of axisymmetric oil interfaces for an oil drop immersed in water. Each curve has a different curvature at the apex of the drop. The distances are normalized by $\sqrt{\sigma /(\Delta \rho g)}$ 
Fig. $11 \mathrm{~A}$ calcite (marble) plate has two plastic films to create a $13 \mu \mathrm{m}$ gap between the plate and the front of an optical cell.

Fig. 12 Displacement of crude oil in narrow gap with (a) brine or with (b) alkaline surfactant solution

Fig. 13 Saturation/concentration profiles in a narrow gap or in a porous rock during displacement of oil by buoyancy. 43

Fig. 14 Phase behavior of MY3 crude oil and different concentrations of

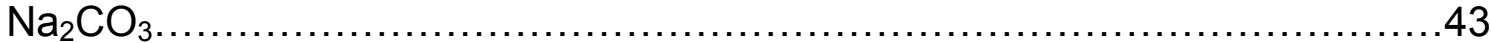

Fig. 15 Phase behavior of MY3 crude oil with $0.05 \%$ (AM) CS-330 .............44

Fig. 16 Phase behavior of MY3 crude oil with $0.05 \%$ (AM) C12-3PO ............44

Fig. 17 Phase behavior of MY3 crude oil with $0.05 \%$ (AM) TDA-4PO ............45

Fig. 18 Phase behavior of MY3 crude oil with $0.05 \%$ (AM) ISOFOL 14T-4.1PO.45

Fig. 19 IFT of MY3 crude oil with $0.05 \%$ (AM) surfactant solution as a function of $\mathrm{Na}_{2} \mathrm{CO}_{3}$ concentration. Water/Oil ratio $=1: 1$.

Fig. 20 IFT of MY3 crude oil with $0.05 \%$ (AM) surfactant solution as a function of water/oil ratio. WOR $=1$ is close to optimum $\mathrm{Na}_{2} \mathrm{CO}_{3}$ concentration...............46

Fig. 21 Phase behavior of MY3 crude oil with $0.2 \%$ (AM) TDA-4PO ............47

Fig. 22 Phase behavior of MY3 crude oil with 1\% (AM) TDA-4PO ..............47

Fig. 23 IFT of MY3 crude oil with $0.05 \%, 0.2 \%$, and $1 \%$ (AM) TDA-4PO as a function of $\mathrm{Na}_{2} \mathrm{CO}_{3}$ concentration. Water/oil ratio $=1: 1$. 48

Fig. 24 Adsorption isotherms of 1:1 CS-330 + TDA-4PO without and with sodium carbonate.

Fig. 25 Adsorption isotherms of TDA-4PO without and with sodium carbonate.49

Fig. 26 Spontaneous imbibition with (a) brine, or (b) alkaline surfactant solution.

Fig. 27 Oil recovery by spontaneous imbibition. .50

Fig. 28 Oil recovery by spontaneous imbibition as function of dimensionless time for gravity drainage. 50

Fig. 29 Oil recovery for spontaneous imbibition as function of dimensionless time for capillary imbibition, assuming IFT of $10^{-3} \mathrm{mN} / \mathrm{m}$. 


\section{INTRODUCTION}

Oil recovery by primary depletion and waterflooding recovers only about one third of the original in place, on the average. The remaining oil can be categorized into: (1) the residual oil in the regions swept by water and (2) the movable oil in the regions unswept or poorly swept by water. This project uses surfactants to reduce the residual oil saturation by both interfacial tension reduction and wettability alteration, the latter in cases where wettability is responsible for retaining oil in the matrix. A factor in the sweep efficiency of a reservoir is the mobility ratio between the resident fluids and the injected fluids. Polymer solution is the traditional method for mobility control in surfactant flooding. This project will evaluate foam as an alternate or supplement to polymer for mobility control. Our objective is to economically increase the recovery efficiency beyond that achieved by waterflooding.

Both unfractured and fractured formations will be addressed in this project. The driving force for displacement of oil in unfractured systems is primarily the pressure gradient developed by displacing fluids from the injection well to the production well. This pressure gradient may be only a small contributor in fractured formations. In this case, spontaneous imbibition is needed to exchange the injected fluid and oil between the fracture and matrix. The driving force for spontaneous imbibition includes capillary pressure gradients and buoyancy, or gravity drainage. The contribution due to capillary pressure gradients may be diminished because of low interfacial tension.

Both sandstone and carbonate formations will be considered. Carbonate formation usually tend to be more oil-wet and fractured compared to sandstone formations. In either case, surfactant adsorption on the mineral surfaces must be minimized. Sodium carbonate is used with anionic surfactants in carbonate formations to reduce adsorption. The alkalinity of the sodium carbonate also generates surfactants in situ by reacting with the naphthenic acids in the crude oil. 


\section{EXECUTIVE SUMMARY}

Twenty four surfactants are compared for their efficacy for oil recovery by surfactant flooding. Surfactant structure - performance relationships are needed for applications with a specified crude oil composition, brine salinity, reservoir temperature, formation mineralogy, and recovery mechanism. The surfactants are characterized by the optimal salinity for a given oil, the level of interfacial tension at optimal conditions, and whether it forms viscous gel or liquid crystalline phases.

An alkaline surfactant process is being developed for enhanced spontaneous imbibition in a fractured, oil-wet, carbonate formation. The carbonate ion of sodium carbonate is a potential determining ion in carbonate formations such as calcite and dolomite. Alteration of the mineral surface to a negative charge aids in the wettability alteration and makes a dramatic reduction in the adsorption of anionic surfactants. Calcium ion concentration is sequestered because of the low solubility product of calcium carbonate. Also the alkali raises the $\mathrm{pH}$, which results in sponification of naphthenic acids to naphthenic soap, a natural surfactant. The naphthenic soap is usually too lypophilic by itself and addition of a synthetic surfactant is needed. Ultra-low interfacial tensions are possible at synthetic surfactant concentrations as low as $0.05 \%$. However, the system is complex because it is a mixture of two surfactants with very different properties.

It is argued that capillarity, governed by wettability and interfacial tension, is responsible for retaining oil in the oil-wet matrix when a fractured, carbonate formation is waterflooded. This is demonstrated by observations with a calcite plate, either in a horizontal configuration or in a narrow, vertical gap. Replacement of brine with alkaline surfactant solution results in mobilization of oil by buoyancy or gravity drainage.

Spontaneous imbibition did not occur when partially oil saturated, dolomite core samples were placed in an imbibition cell filled with brine. Spontaneous imbibition occurred when the brine was replaced with alkaline surfactant solution. Scaling of the rate of recovery indicated that dominant mechanism for recovery was gravity drainage. 
Subtask 1.1 Identifying and synthesizing improved, cost-effective surfactants

Start Date: June $2003 \quad$ Expected Completion Date: May 2004

Description of Surfactants. Eighteen surfactants based on the alcohol propoxy sulfate structure have been synthesized upon our request by Sasol North America Inc., the world's largest manufacturer of surfactants and surfactant intermediates. Additional surfactants are being supplied by Harcros Chemical a specialty surfactants manufacturer. Based on our experience with surfactant/oil phase behavior, these surfactants are potential candidates for the EOR technology. The hydrophobe portion of the candidates is a branched alcohol with $\mathrm{C}_{12}$ to $\mathrm{C}_{15}$ length. The branching disrupts structure thus minimizing gelling and liquid crystal formation at low temperatures and enables quicker equilibration time for microemulsion formation and the resulting low interfacial tension. The branching consists of methyl groups or larger alkyl groups that extend all the way to $\mathrm{C}_{4}$ as in the guerbet alcohols. One of the alcohol hydrophobes trademarked Safol $\AA^{\circledR}$ is a newly introduced product prepared by Fischer-Tropsch synthesis of gasified coal, which uncouples the cost of this alcohol with that of oil and gas. Safol $\otimes$ alcohols achieve the same effect as branching by containing a variety of chemical structures which minimize ordered arrays of similar structures and the attendant, undesirable surfactant properties.

The overall structure of the candidate surfactants is:

(branched alcohol) - (propoxyl groups $)_{n}$ - (sulfate)

By varying the number of propoxyl groups the surfactant exhibits varying ratios of hydrophilicity to hydrophobicity (often referred to as the hydrophile:lipophile balance or HLB). However, unlike ethoxyl (EO) moieties the increasing propoxyl (PO) groups increases both the hydrophobicity and lypophilicity whereas increasing EO increases hydrophilicity. Thus, the propoxy chain appears to be equally comfortable on either side of the water-oil interface. This can explain the low interfacial tensions that can be achieved with these surfactants.

By varying the alcohol hydrophobe and the number of PO groups, together with shifting the hydrophobicity with increasing cation counterion concentration (i.e., optimal salinity), it should be possible to find the right water:oil phase behavior for any oil.

Table 1.1 lists the surfactants that have been synthesized and are available for testing. Most of the surfactants are alcohol propoxy sulfates with the indicated alcohol structure and moles of PO. One of the surfactants has both ethylene oxide and propylene oxide units. Trade names are given but it should be noted that none of these surfactants currently are items of commerce. 
Table 1.1. Candidate Surfactants: Description \& Tradenames

\begin{tabular}{|c|c|c|}
\hline Product Name & $\begin{array}{c}\text { Alcohol Carbon Chain Length \& } \\
\text { (Trademark) }\end{array}$ & Moles PO \\
\hline $\begin{array}{l}\text { TDA-4PO-sulfate } \\
\text { (Harcros Chemical) }\end{array}$ & $\mathrm{C}_{13} ;$ Isotridecanol (Ethyl Corp. TDA) & 4 \\
\hline $\begin{array}{l}\text { TDA-1EO-4PO- } \\
\text { sulfate (Harcros } \\
\text { Chemical) }\end{array}$ & $\mathrm{C}_{13} ;$ Isotridecanol (Ethyl Corp. TDA) & 4 \\
\hline $\begin{array}{l}\text { TDA-8PO-sulfate } \\
\text { (Harcros Chemical) }\end{array}$ & $\mathrm{C}_{13}$; Isotridecanol (Ethyl Corp. TDA) & 8 \\
\hline Alfoterra ${ }^{\circledR} 13$ & $\mathrm{C}_{13} ;$ Isotridecanol (Marlipal) & 3 \\
\hline Alfoterra $₫ 15$ & $\mathrm{C}_{13} ;$ Isotridecanol (Marlipal) & 5 \\
\hline Alfoterra $® 18$ & $\mathrm{C}_{13} ;$ I Isotridecanol (Marlipal) & 8 \\
\hline Alfoterra $囚 23$ & $\mathrm{C}_{12}\left(\mathrm{C}_{6}+\mathrm{C}_{6}\right)$ Guerbet (Isofol $\left.\circledast 12\right)$ & 3 \\
\hline Alfoterra $® 25$ & $\mathrm{C}_{12}\left(\mathrm{C}_{6}+\mathrm{C}_{6}\right)$ Guerbet (Isofol $\left.\AA 12\right)$ & 5 \\
\hline Alfoterra $₫ 28$ & $\mathrm{C}_{12}\left(\mathrm{C}_{6}+\mathrm{C}_{6}\right)$ Guerbet (Isofol $(12)$ & 8 \\
\hline Alfoterra $® 33$ & $\mathrm{C}_{14}\left(\mathrm{C}_{8}+\mathrm{C}_{6}\right)$ Guerbet (Isofol $\left.囚 14 \mathrm{~T}\right)$ & 3 \\
\hline Alfoterra $囚 35$ & $\mathrm{C}_{14}\left(\mathrm{C}_{8}+\mathrm{C}_{6}\right)$ Guerbet (Isofol $\left.\circledast 14 \mathrm{~T}\right)$ & 5 \\
\hline Alfoterra ${ }^{\circledR} 38$ & 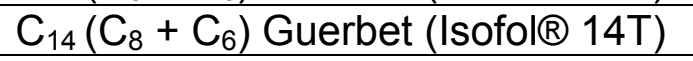 & 8 \\
\hline Alfoterra $囚 43$ & $\mathrm{C}_{12} \& \mathrm{C}_{13}$ (Isalchem $\left.{ }^{\mathrm{TM}} 123\right)$ & 3 \\
\hline Alfoterra® 45 & $\mathrm{C}_{12} \& \mathrm{C}_{13}$ (Isalchem $\left.{ }^{\mathrm{TM}} 123\right)$ & 5 \\
\hline Alfoterra $囚 48$ & $\mathrm{C}_{12} \& \mathrm{C}_{13}$ (Isalchem $\left.{ }^{\mathrm{TM}} 123\right)$ & 8 \\
\hline Alfoterra ${ }^{\circledR} 53$ & $\mathrm{C}_{14} \& \mathrm{C}_{15}$ (Isalchem $\left.{ }^{\mathrm{TM}} 145\right)$ & 3 \\
\hline Alfoterra $® 55$ & $\mathrm{C}_{14} \& \mathrm{C}_{15}$ (Isalchem $\left.{ }^{\mathrm{TM}} 145\right)$ & 5 \\
\hline Alfoterra $囚 58$ & $\mathrm{C}_{14} \& \mathrm{C}_{15}$ (Isalchem $\left.^{\mathrm{TM}} 145\right)$ & 8 \\
\hline Alfoterra $囚 63$ & $\mathrm{C}_{12} \& \mathrm{C}_{13}($ Safol $囚 23)$ & 3 \\
\hline Alfoterra® 65 & $\mathrm{C}_{12} \& \mathrm{C}_{13}$ (Safol@ 23) & 5 \\
\hline Alfoterra® 68 & $\mathrm{C}_{12} \& \mathrm{C}_{13}(\mathrm{Safol} \circledast 23)$ & 8 \\
\hline & & Moles EO \\
\hline N67-3S & $\mathrm{C}_{16} \& \mathrm{C}_{17}(95 \%$ branched) (Shell) & 3 \\
\hline IOS15-18 & $\mathrm{C}_{15} \& \mathrm{C}_{18}$ (internal olefin sulfonate) & 0 \\
\hline CS-330 & $\mathrm{C}_{12}$ (Stepan) & 3 \\
\hline
\end{tabular}

Two surfactants were contributed by Shell and a surfactant from Stepan are listed at the end of the above table. The internal olefin sulfonate is a lower molecular weight member of the class of surfactant used by Shell in their alkali surfactant flood. The ethoxylated sulfate, N67-3S, is about 5\% linear and 95\% randomly branched with on average about 1.5 methyl branches per molecule. It is prepared from a mixture of $\mathrm{C}_{16}$ and $\mathrm{C}_{17}$ alcohols. This may be contrasted with the familiar, NEODOL 25-3S, which is about $20 \%$ branched with mostly 2-methyl branching. It is prepared from a blend of $\mathrm{C}_{12}$ through $\mathrm{C}_{15}$ alcohols. The Stepan, CS-330 is similar to NEODOL 25-3S.

Phase behavior experiments are being conducted or have been completed using decane as the oil and $1.5 \%$ active surfactant concentration at 
$60^{\circ} \mathrm{C}$. This initial screening is to gain information on equilibration times, adverse phase behavior such as gels or liquid crystal formation, and the optimum oil solubilization parameter, $\sigma^{*}$, and salinity, $S^{*}$. Fig. 1.1 below shows an example plot of the oil and water solubilization ratios and the optimum values of $S^{*}$ and $\sigma^{*}$ (where the oil and water solubilization curves in the middle phase microemulsion intersect).

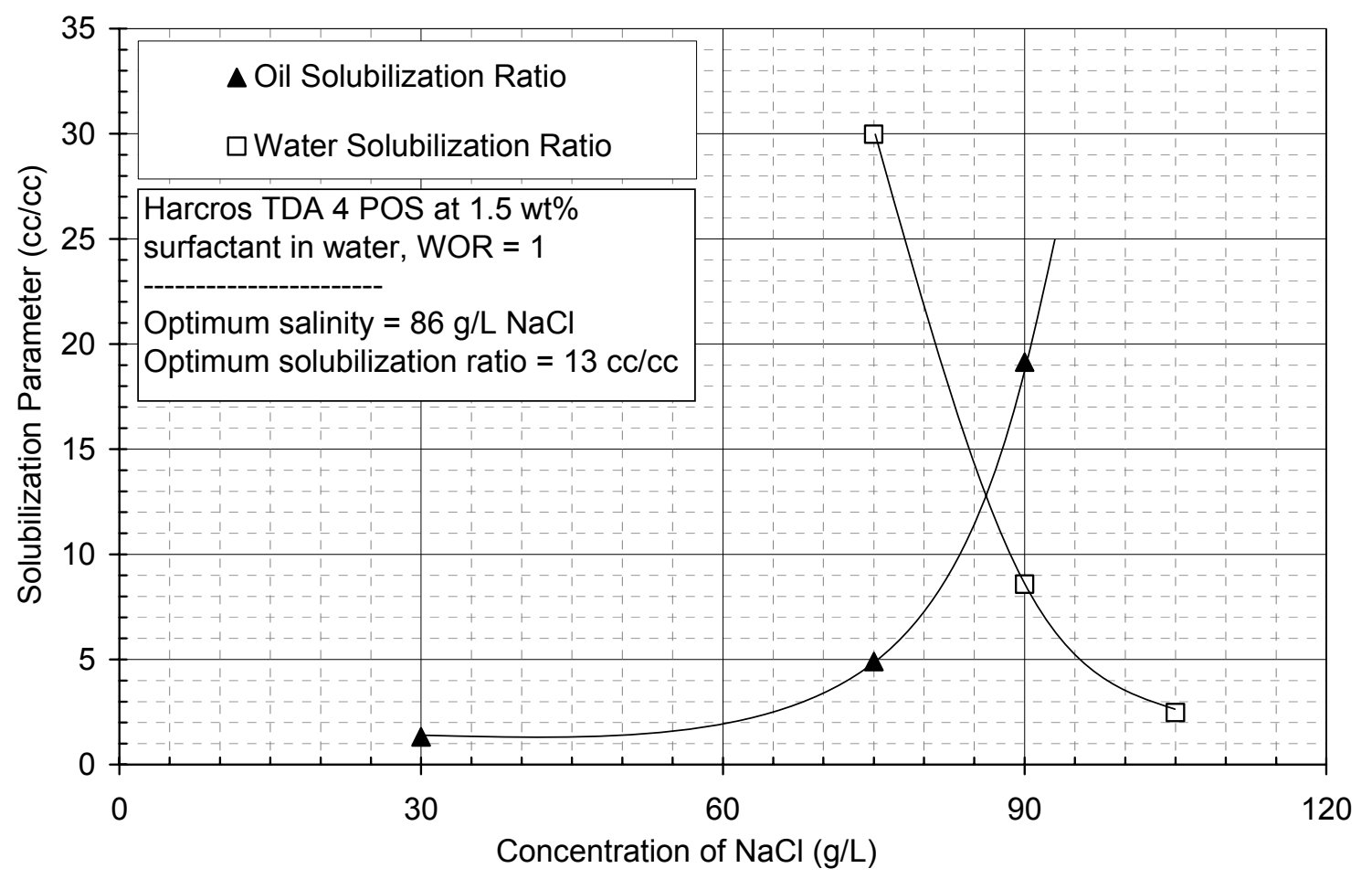

Fig. 1.1 - Example of a Phase Diagram

The $S^{*}$ and $\sigma^{*}$ values measured to date are given in Table 1.2. The two TDA surfactants with $8 \mathrm{POs}$ have exceptionally high values of solubilization ratio. The value at optimum salinity for TDA-8PO-sulfate is 36 . Five systems have not yet equilibrated. These systems are indicated as "not equilibrated" in the table. Some of the samples for these five systems also have viscous phases such as gels and may not be suitable for further testing.

The surfactant systems marked with two asterisks indicate reasonable systems where one or two of the phase behavior tubes are slower to equilibrate than the rest. The results shown include interpolated values that may change with time and will continue to be observed. The best systems identified at the end of these experiments will be tested with crude oil samples to identify the best overall formulation for use with crude oils. 
Table 1.2: Phase Behavior Experiments with Decane, 1.5\% Surfactant and 0.05 wt $\% \mathrm{Na}_{2} \mathrm{CO}_{3}$

\begin{tabular}{|c|c|c|c|}
\hline Product Name & $\begin{array}{l}\text { Alcohol Carbon Chain Length \& } \\
\text { (Trademark) }\end{array}$ & $\begin{array}{l}\text { Optimum } \\
\text { Salinity } \\
\mathrm{S}^{*}(\mathrm{~g} / \mathrm{L} \\
\mathrm{NaCl}) \\
@ 60^{\circ} \mathrm{C}\end{array}$ & $\begin{array}{l}\text { Optimum Oil } \\
\text { Solubilizatio } \\
\text { n Ratio } \sigma^{*} \\
\text { (cc/cc) } \\
@ 60^{\circ} \mathrm{C}\end{array}$ \\
\hline $\begin{array}{l}\text { TDA-4PO-sulfate } \\
\text { (Harcros } \\
\text { Chemical) }\end{array}$ & $\begin{array}{l}\mathrm{C}_{13} ; \text { Isotridecanol (Ethyl Corp. } \\
\text { TDA) }\end{array}$ & 90 and $86^{*}$ & 12 and $13^{*}$ \\
\hline $\begin{array}{l}\text { TDA-1EO-4PO- } \\
\text { sulfate (Harcros } \\
\text { Chemical) }\end{array}$ & $\begin{array}{l}\mathrm{C}_{13} \text {; Isotridecanol (Ethyl Corp. } \\
\text { TDA) }\end{array}$ & 108 & 6 \\
\hline $\begin{array}{l}\text { TDA-8PO-sulfate } \\
\text { (Harcros } \\
\text { Chemical) }\end{array}$ & $\begin{array}{l}\mathrm{C}_{13} \text {; Isotridecanol (Ethyl Corp. } \\
\text { TDA) }\end{array}$ & 36 & 36 \\
\hline Alfoterra ${ }^{\circledR} 13$ & $\mathrm{C}_{13}$; Isotridecanol (Marlipal) & 88 & 16 \\
\hline Alfoterra $₫ 15$ & $\mathrm{C}_{13} ;$ Isotridecanol (Marlipal) & 68 & 17 \\
\hline Alfoterra $₫ 18$ & $\mathrm{C}_{13} ;$ Isotridecanol (Marlipal) & 32 & 38 \\
\hline Alfoterra $₫ 23$ & $\mathrm{C}_{12}\left(\mathrm{C}_{6}+\mathrm{C}_{6}\right)$ Guerbet (Isofol $\left.\circledast 12\right)$ & $73^{* *}$ & $7^{* *}$ \\
\hline Alfoterra $® 25$ & $\mathrm{C}_{12}\left(\mathrm{C}_{6}+\mathrm{C}_{6}\right)$ Guerbet (Isofol $\left.\circledast 12\right)$ & $35^{\star *}$ & $12^{* *}$ \\
\hline Alfoterra ${ }^{\circledR} 28$ & $\mathrm{C}_{12}\left(\mathrm{C}_{6}+\mathrm{C}_{6}\right)$ Guerbet (Isofol $\left.\circledast 12\right)$ & $\begin{array}{c}\text { Not } \\
\text { equilibrated }\end{array}$ & $\begin{array}{c}\text { Not } \\
\text { equilibrated }\end{array}$ \\
\hline Alfoterra $\AA 33$ & $\begin{array}{l}\mathrm{C}_{14}\left(\mathrm{C}_{8}+\mathrm{C}_{6}\right) \text { Guerbet (Isofol } \Omega \\
14 \mathrm{~T})\end{array}$ & $32^{* *}$ & $3^{* *}$ \\
\hline Alfoterra $₫ 35$ & $\begin{array}{l}\mathrm{C}_{14}\left(\mathrm{C}_{8}+\mathrm{C}_{6}\right) \text { Guerbet (Isofol }{ }_{1} \\
14 \mathrm{~T})\end{array}$ & $\begin{array}{c}\text { Not } \\
\text { equilibrated }\end{array}$ & $\begin{array}{c}\text { Not } \\
\text { equilibrated }\end{array}$ \\
\hline Alfoterra $\AA^{\circledR} 38$ & $\begin{array}{l}\mathrm{C}_{14}\left(\mathrm{C}_{8}+\mathrm{C}_{6}\right) \text { Guerbet (Isofol } 8 \\
14 \mathrm{~T})\end{array}$ & $22^{* *}$ & $2^{* *}$ \\
\hline Alfoterra $₫ 43$ & $\mathrm{C}_{12} \& \mathrm{C}_{13}\left(\right.$ Isalchem $\left.{ }^{\mathrm{TM}} 123\right)$ & $95^{\star *}$ & $15^{* *}$ \\
\hline Alfoterra $₫ 45$ & $\mathrm{C}_{12} \& \mathrm{C}_{13}\left(\right.$ Isalchem $\left.{ }^{\mathrm{TM}} 123\right)$ & $\begin{array}{c}\text { Not } \\
\text { equilibrated }\end{array}$ & $\begin{array}{c}\text { Not } \\
\text { equilibrated }\end{array}$ \\
\hline Alfoterra $₫ 48$ & $\mathrm{C}_{12} \& \mathrm{C}_{13}$ (Isalchem ${ }^{\mathrm{TM}}$ 123) & $\begin{array}{c}\text { Not } \\
\text { equilibrated }\end{array}$ & $\begin{array}{c}\text { Not } \\
\text { equilibrated }\end{array}$ \\
\hline Alfoterra $₫ 53$ & $\mathrm{C}_{14} \& \mathrm{C}_{15}$ (Isalchem $\left.{ }^{\mathrm{TM}} 145\right)$ & $55^{\star *}$ & $6^{* *}$ \\
\hline Alfoterra $® 55$ & $\mathrm{C}_{14} \& \mathrm{C}_{15}$ (Isalchem ${ }^{\mathrm{TM}}$ 145) & $56^{* *}$ & $2^{* *}$ \\
\hline Alfoterra $\AA^{\circledR} 58$ & $\mathrm{C}_{14} \& \mathrm{C}_{15}\left(\right.$ Isalchem $\left.{ }^{\mathrm{TM}} 145\right)$ & $\begin{array}{c}\text { Not } \\
\text { equilibrated }\end{array}$ & $\begin{array}{c}\text { Not } \\
\text { equilibrated }\end{array}$ \\
\hline Alfoterra ${ }^{\circledR} 63$ & & 108 & 3 \\
\hline Alfoterra $\AA^{8} 65$ & $\mathrm{C}_{12} \& \mathrm{C}_{13}($ Safol $\circledast 23)$ & 95 & 9 \\
\hline Alfoterra $₫ 68$ & $\mathrm{C}_{12} \& \mathrm{C}_{13}(\mathrm{Safol} \circledast 23)$ & 68 & 5 \\
\hline
\end{tabular}

* - results from two surfactant batches

** preliminary data since samples not equilibrated yet after 10 days

The viscosity of some of the middle phase microemulsions has also been measured. Fig. 1.2 below shows data for samples with salinities of $90 \mathrm{~g} / \mathrm{L}$ and 
$105 \mathrm{~g} / \mathrm{L} \mathrm{NaCl}$. The sample at $90 \mathrm{~g} / \mathrm{L}$ shows a non-Newtonian behavior and the viscosity at low shear rate is higher than desirable for enhanced oil recovery.

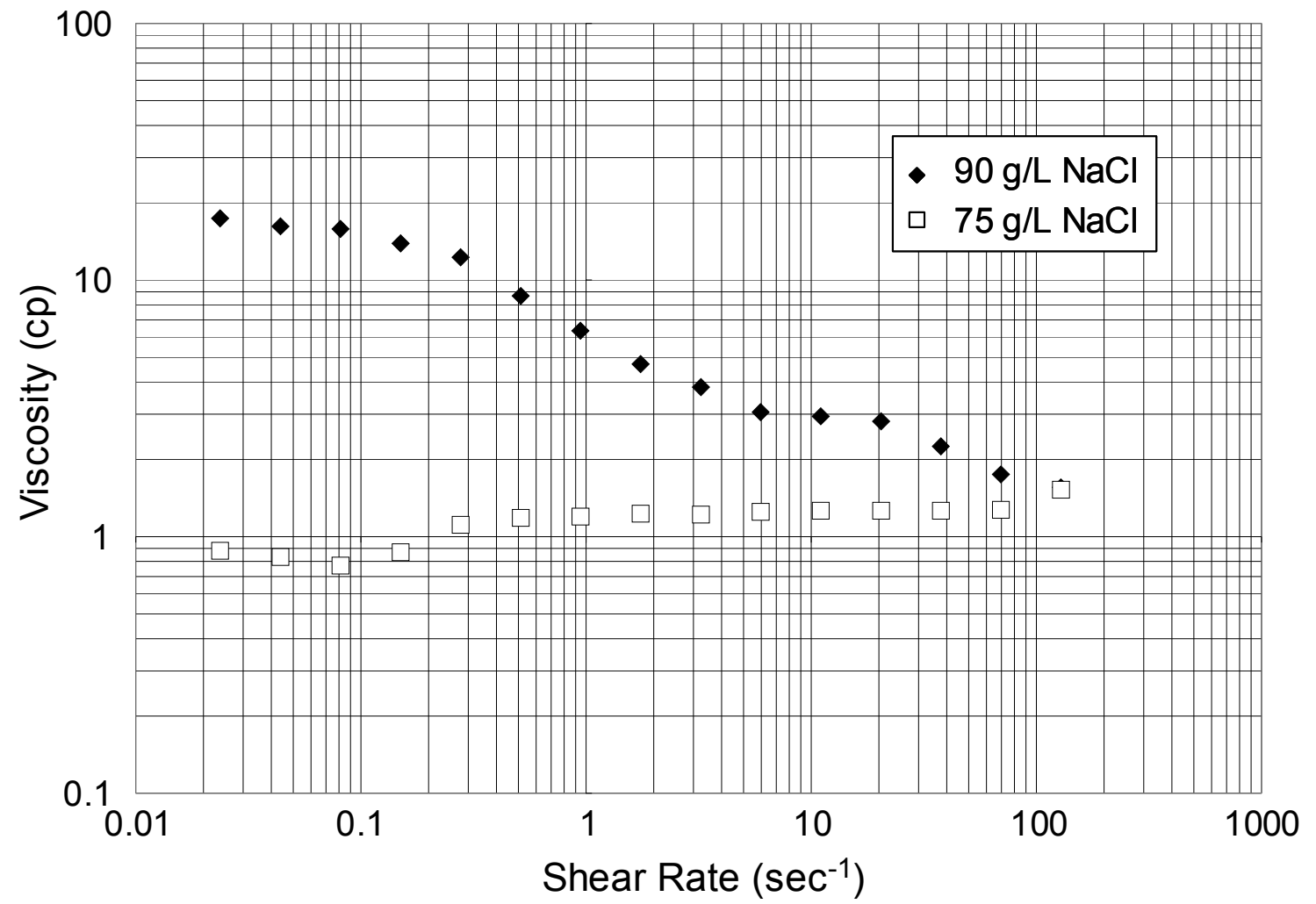

Fig. 1.2 Viscosity vs. Shear Rate for Middle Phase Microemulsion in Harcros TDA-4PO-sulfate sodium salt with Decane at $60{ }^{\circ} \mathrm{C}$

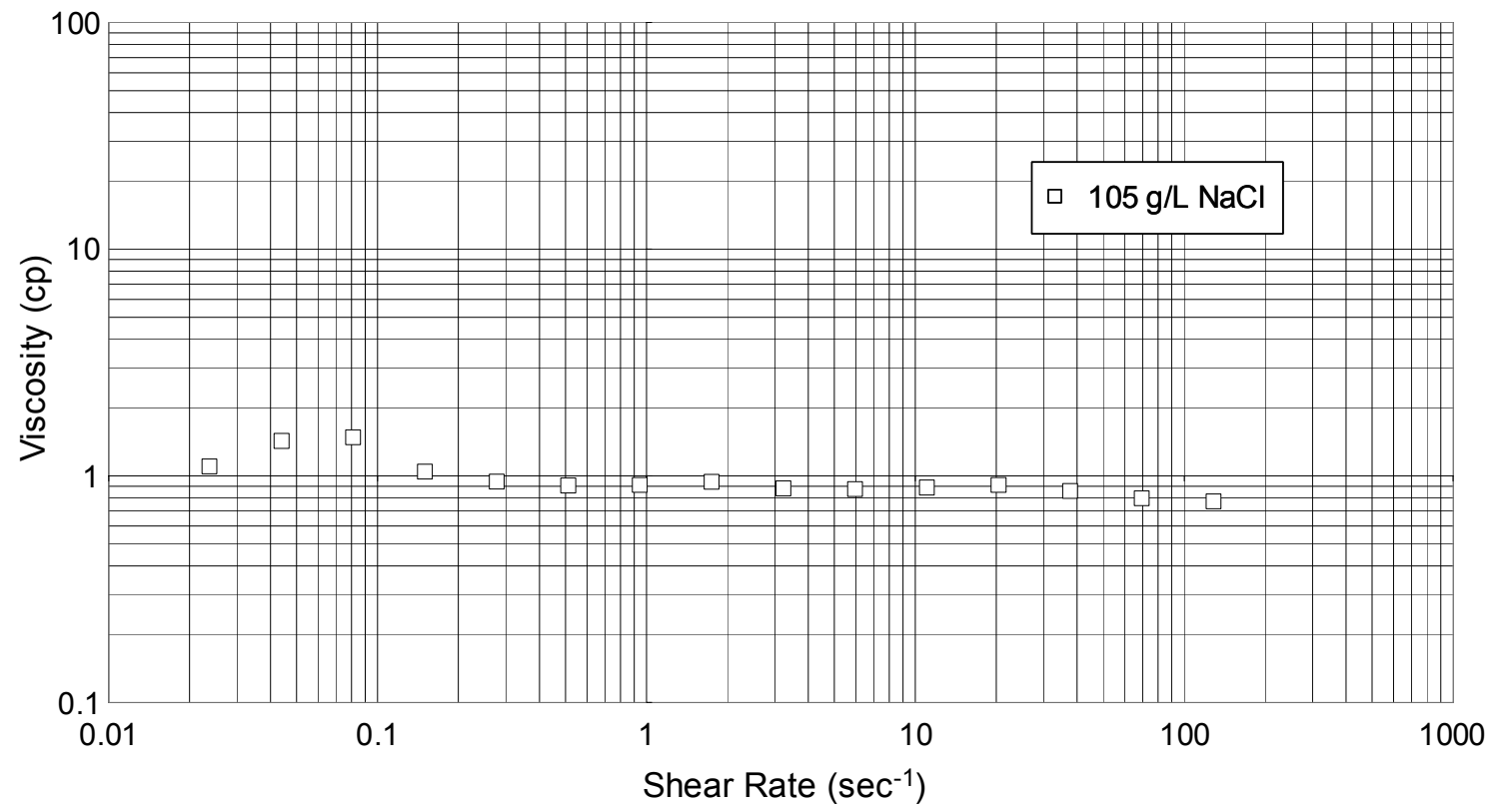

Fig. 1.3 Viscosity vs. Shear Rate for Middle Phase Microemulsion in Harcros TDA-1EO-4PO-sulfate sodium salt with Decane at $60^{\circ} \mathrm{C}$ 
Figure 3 shows the microemulsion viscosity of a sample near optimum salinity. This sample displays low viscosity and Newtonian behavior both of which are desirable traits for a good surfactant system.

\title{
Subtask 1.2 Surfactant tailoring for crude oils and phase behavior
} Start Date: June $2003 \quad$ Expected Completion Date: May 2004

The three best surfactant formulations identified in Subtask 1.1 will be tested with crude oils to compare the difference in phase behavior of the surfactant when the oil is changed. The results of these experiments will be used to correlate optimum salinity and phase behavior to the oil and surfactant characteristics. The phase behavior experiments with the first crude oil samples are underway. The crude oil is from the Yates field. The results of these initial tests will be used to add other crude oils to the study. We have also initiated some studies with high concentrations of sodium carbonate and Yates crude oil and have measured the IFT of some of these samples. Preliminary IFT data show values on the order of $0.02 \mathrm{dyne} / \mathrm{cm}$.

Task 2 Phase behavior, adsorption, and composition changes during displacement

The progress on this Task is included in the revised manuscript of SPE 80988, which was resubmitted for publication in January 2004.

\section{Surface Chemistry of Oil Recovery From Fractured, Oil-Wet, Carbonate Formations}

George Hirasaki (SPE) and Danhua Leslie Zhang (SPE), Rice University

Copyright 2003, Society of Petroleum Engineers Inc.

This paper was originally prepared for presentation at the SPE International Symposium on Oilfield Chemistry held in Houston, Texas, U.S.A., 5-8 February 2003.

\begin{abstract}
Oil recovery by water flooding in fractured formations is often dependent on spontaneous imbibition. However, spontaneous imbibition is often insignificant in oil-wet, carbonate rocks. Sodium carbonate and anionic surfactant solutions are evaluated for enhancing oil recovery by spontaneous imbibition from oil-wet carbonate rocks. Crude oil samples must be free of surface-active contaminants to be representative of the reservoir. Calcite, which is normally positively charged, can be made negative with sodium carbonate. The ease of wettability
\end{abstract}


alteration is a function of the aging time and temperature and the surfactant formulation.

\section{Introduction}

Much oil remains in fractured, carbonate oil reservoirs after waterflooding and in some cases in paleo-transition zones, which result from the oil/water contact moving upward before discovery. The high remaining oil saturation is due to a combination of poor sweep in fractured reservoirs and the formation being preferentially oil-wet during imbibition ${ }^{1,2}$. (Imbibition is defined as the process of water displacing oil. Spontaneous imbibition is defined as imbibition that takes place by action of capillary pressure and/or buoyancy when a core sample or matrix block is surrounded by brine.) Poor sweep is not an issue in paleotransition zones but yet the remaining oil saturation may still be significant.

There are several reasons for high remaining oil saturation in fractured, oil-wet, carbonate formations. If the formation is preferentially oil-wet, the matrix will retain oil by capillarity and high oil saturation transition zones will exist where the upward oil film flow path is interrupted by fractures. This is illustrated in Fig. 1 , which shows the oil retained by oil-wet capillaries of different radii. The height of the capillary retained oil column is proportional to the product of interfacial tension and cosine of the contact angle and is inversely proportional to the capillary radius. In oil-wet systems, oil is the phase contacting the rock surfaces, and surface trapping is likely to be particularly important in rocks with highly irregular surfaces and large surface areas ${ }^{1}$, Fig. 2.

The objective of this investigation is to develop a process to overcome the mechanisms for oil retention illustrated by Figs. $1 \& 2$. Oil is retained by wettability and capillarity. Thus by altering the wettability to preferentially waterwet conditions and reducing the interfacial tension to ultra-low values, the forces that retain oil can be overcome. Introducing an injected fluid into the matrix of a fractured formation is challenging because the injected fluid will flow preferentially in the fractures rather than through the matrix. Thus the process must be designed to cause spontaneous imbibition of the injected fluid from the fracture system into the matrix, as illustrated in Fig. 3. Spontaneous imbibition by capillarity may no longer be significant because of low interfacial tension. However, if wettability is altered to preferentially water-wet conditions and/or capillarity is diminished through ultra-low interfacial tensions, buoyancy will still tend to force oil to flow upward and out of the matrix into the fracture system. The injected fluid in the fractures will replace the displaced oil in the matrix and thus the invasion of the injected fluid into the matrix will continue as long as oil flows out of the matrix.

Spontaneous imbibition by capillarity is an important mechanism in oil recovery from fracture reservoirs. A recent survey by Morrow and Mason reviews the state-of-the-art ${ }^{3}$. They state that spontaneous imbibition rates with different wettability can be several orders of magnitude slower and displacement efficiencies range from barely measurable to better than very strongly water-wet. 
The primary driving force for spontaneous imbibition in strongly water-wet conditions is usually the capillary pressure. Reduction of interfacial tension reduces the contribution of capillary imbibition. Buoyancy, as measured by the product of density difference and the acceleration of gravity then becomes the dominant parameter governing the displacement, even if oil is the wetting phase ${ }^{4}$.

Application of surfactants to alter wettability and thus enhance spontaneous imbibition has been investigated by Austad, et al. ${ }^{7-11}$ with chalk and dolomite cores. Chen, et al. ${ }^{12}$, investigated enhanced spontaneous imbibition with nonionic surfactants. Spinler, et al. ${ }^{13}$, evaluated 46 surfactants for enhanced spontaneous imbibition in chalk formations. Standnes, et al. ${ }^{11}$ and Chen, et al. ${ }^{12}$ used either nonionic or cationic surfactant with a strategy to alter wettability but avoid ultra-low tensions. The work presented here differs from the previous work in that sodium carbonate and anionic surfactants are used to both alter wettability and reduce interfacial tension to ultra-low values. The primary recovery mechanism in this work is buoyancy or gravity drainage. Wettability alteration and ultra-low interfacial tensions are designed to minimize the oil retention mechanisms.

\section{Crude Oil Samples}

It is important to have a representative crude oil sample when designing an EOR process. Since the process is based on surface phenomena, it is important that the crude oil is free of surface-active materials such as emulsion breaker, scale inhibitor, or rust inhibitor. A simple test for contamination is to measure the interfacial tension (IFT) of the crude oil sample with synthetic brine. Fig. 4 is a plot of the oil/brine IFT of several crude oil samples from the same field. These measurements were made with a pendant drop apparatus with automatic video data acquisition and fit to the Young-Laplace equation. Samples MY1 and MY2 have low initial IFT that further decreases with time. This is an indication that these samples contain a small amount of surface-active material, which slowly diffuses to the interface and reduces the IFT. Samples MY3 - MY6 have a much larger initial IFT. Even though there is some decrease in IFT with time, the IFT remains in the range of $20-30 \mathrm{mN} / \mathrm{m}$. Some early experiments were made with MY1 before we were aware of the contamination but the later experiments were made with MY3.

The properties of the crude oil samples are listed in Table 1. The higher acid number and viscosity for MY1 compared to the other samples suggest that it may be an outlier. The wettability of the oil samples were compared by pressing an oil drop in brine against a calcite (marble) or glass plate for 5-10 minutes, withdrawing the drop, and measuring the water advancing contact angle after motion has ceased. The water advancing contact angles of MY1 and MY3 against calcite or glass after aging time of 5-10 minutes are compared in Fig. 5. Clearly, MY1 and MY3 crude oils have different wettability properties. 


\section{Formation Wettability}

Spontaneous imbibition in carbonate formations often does not occur or is slow compared to sandstone formations. ${ }^{14-19}$ Treiber, Archer, and Owens ${ }^{14}$ measured the equilibrated water advancing contact angles of fifty crude oils. They found that of the carbonate reservoir-crude oil-water systems tested, $8 \%$ were waterwet; $8 \%$ intermediate; and $84 \%$ oil-wet. This is in contrast to $43 \%$ water-wet; $7 \%$ intermediate-wet; and $50 \%$ oil-wet for silicate formation reservoirs.

Freedman, et al. ${ }^{20}$, evaluated the wettability of Bentheim sandstone, Berea sandstone, and the dolomite formation of the present investigation. A crude oil from the North Sea was used for the evaluation. Water would spontaneously imbibe into the sandstone formation materials but no measurable spontaneous imbibition occurred in the dolomite samples during 24 hours. The dolomite cores were partially water flooded to an intermediate saturation and the NMR relaxation time distribution of the remaining oil was measured. The relaxation time distributions of the crude oil in the sandstones were identical to that of the bulk oil, indicating that the sandstones were water-wet. However, the relaxation time distribution of the crude oil in the dolomite sample was shortened, indicating surface relaxation of the oil. This occurs due to oil making contact with the pore walls. Thus, this is evidence of oil wetting the pore walls in the dolomite sample.

The wettability of the MY3 crude oil was evaluated by measuring the water advancing contact angle on calcite (marble) plates. The plates were solvent cleaned, polished on a diamond lap to remove the surface layer, aged in $0.1 \mathrm{M}$ $\mathrm{NaCl}$ brine overnight, and aged in the crude oil for 24 hours, either at room temperature or $80^{\circ} \mathrm{C}$. The reservoir is close to room temperature but elevated temperature aging was used to compensate the short aging time compared to geological time. Photographs of an oil drop in brine on the upper calcite surface after all motion had stopped are shown in Fig. 6. It is clear that the water advancing contact angle is near $180^{\circ}$, i.e., it is oil-wet. It should be noted that MY3 aged for only 5-10 minutes, shown earlier in Fig. 5, had an advancing contact angle of only $50^{\circ}$. These results demonstrate the importance of aging time on wettability.

One of the most important factors in the determination of the wettability of crude oil-brine-mineral systems is the electrical or zeta potential of the crude oil/brine interface and of the mineral/brine interface ${ }^{21-23}$. The zeta potentials of these interfaces as a function of $\mathrm{pH}$ are shown in Fig. 7. The zeta potential of the MY1 crude oil is negative for $\mathrm{pH}$ greater than 3 . This is due to the dissociation of the naphthenic acids in the crude oil with increasing $\mathrm{pH}$. The surface of calcite ${ }^{24-}$ ${ }^{31}$ is positive for $\mathrm{pH}$ less than 9 when the only electrolytes are $0.02 \mathrm{M} \mathrm{NaCl}$ and $\mathrm{NaOH}$ or $\mathrm{HCl}$ to adjust $\mathrm{pH}$. The opposite charge between the oil/brine and mineral/brine surfaces results in an electrostatic attraction between the two interfaces, which tend to collapse the brine film and bring the oil in direct contact with the mineral surface. Thus this system can be expected to be non-water-wet around neutral $\mathrm{pH}^{32,33}$. However, this figure also shows that the zeta potential of calcite is negative even to neutral $\mathrm{pH}$ when the brine is $0.1 \mathrm{~N} \mathrm{Na}_{2} \mathrm{CO}_{3} / \mathrm{NaHCO}_{3}$ plus $\mathrm{HCl}$ to adjust $\mathrm{pH}$. This is because the potential determining ions for the 
calcite surface are $\mathrm{Ca}^{2+}, \mathrm{CO}_{3}{ }^{2-}$ and $\mathrm{HCO}^{3-}$. An excess of the carbonate/bicarbonate anions makes the surface negatively charged. If both the crude oil/brine and calcite/brine interfaces are negatively charged, there will be an electrical repulsion between the two surfaces, which tends to stabilize a brine film between the two surfaces. Thus a system with brine containing sufficient excess carbonate/bicarbonate ions may be expected to have a preference to be water-wet, compared to in the absence of excess carbonate ions.

Figs. 8 and 9 illustrate the effect of alkaline surfactant solutions on wettability alteration of a calcite (marble) plate that has been aged in crude oil either at room temperature or at $80^{\circ} \mathrm{C}$. The oil-wet systems, with brine as the surrounding fluid, Fig. 8(a) and Fig. 9(a) are the same as that shown in Fig. 6(a) and $6(\mathrm{~b})$. The displacement of oil by reduction of the interfacial tension and the alteration of the wettability upon replacement of the brine with $0.05 \%$ CS-330 / $0.5 \mathrm{M} \mathrm{Na}_{2} \mathrm{CO}_{3}$ are shown as a function of time. Both systems showed the oil streaming from the surface at early times as a result of the reduction in interfacial tension, Fig. 8(b) and 9(b). Later, small oil drops remaining on the marble plate are observed with higher magnification and the change in contact angle can be observed, Fig. 8(c)-(f) and 9(c)-(f).

The observation of the oil streaming off the plate as surfactant reduces the interfacial tension and alters the contact angle is explained as follows. An oil drop on the upper surface of a solid immersed in brine is not stable for drop dimensions such that the Bond number, $N_{B}=\frac{\Delta \rho g L^{2}}{\sigma}$, is the order of unity or greater. Fig. 10 illustrates possible hydrostatic shapes of axisymmetric oil drops 34,35. The length scales are made dimensionless with respect to the capillary constant, $\sqrt{\sigma /(\Delta \rho g)}$. The different curves only have different dimensionless curvature at the apex of the drop. The interface intersects the solid surface at the point where the inclination angle of the interface is equal to the contact angle with the substrate. Suppose the $L$ in the Bond number is the equatorial radius if the contact angle is $90^{\circ}$ or less; and is the radius of the contact line if the contact angle is larger than $90^{\circ}$. The Bond number of a drop in Fig. 10 is then the square of the dimensionless radius to the equator or to the contact line. The maximum hydrostatic Bond number from Fig. 10 ranges from 0.25 for contact angles less than $90^{\circ}$ to 10 for contact angles approaching $180^{\circ}$. Thus larger contact angles can have larger hydrostatic drop size, for the same IFT.

The definition of the Bond number implies that the maximum hydrostatic oil drop size is proportional to the square root of the interfacial tension. As the interfacial tension was reduced to ultra-low values, the large oil drop was unstable and small drops streamed off. The observation that the oil drop size became $10^{-2}$ smaller when brine was replaced by alkaline surfactant solution is consistent with the observation that the IFT was $10^{-4}$ smaller, i.e., reduced from $30 \mathrm{mN} / \mathrm{m}$ to about $3 \times 10^{-3} \mathrm{mN} / \mathrm{m}$. Also, for the same interfacial tension, oil drops with smaller contact angles are smaller than drops with larger contact angles. 
Alteration of wettability also contributes to displacement of the oil. Fig. 8(c)-(f) shows the wettability being altered from strongly oil-wet to preferentially water-wet for the plate that was aged 24 hours in crude oil at room temperature. An oil drop becomes unstable and detaches as the contact angle approaches a small value. Fig. 9(c)-(f) shows that the plate that was aged 24 hours in crude oil at $80^{\circ} \mathrm{C}$ altered to intermediate wet conditions during the 4- day period of observation. Fig. 9(c)\&(d) is one drop and Fig. 9(e)\&(f) is another drop. No further change was observed after the first day to the fourth day.

Similar observations were made for systems with TDA-4PO and a blend of CS-330 and TDA-4PO. The sodium carbonate concentrations were near that which gave minimum interfacial tension. Besides initially equilibrating the marble plate in $\mathrm{NaCl}$ brine, some experiments had the plate initially equilibrated in sodium carbonate solution or in alkaline surfactant solution. The advancing contact angle at the end of the observation period ranged from preferentially water-wet to intermediate-wet. These variations did not result in a systematic change in wettability compared to the effect of aging time and temperature in crude oil.

\section{Spontaneous Imbibition}

Spontaneous imbibition is most commonly associated with counter-current capillary imbibition in systems that are preferentially water-wet ${ }^{3}$. If the interfacial tension is very low, capillarity becomes less important compared to buoyancy ${ }^{4}$. However, for systems that are preferentially oil-wet, spontaneous imbibition of brine usually does not occur and capillarity is the mechanism that retains oil in the matrix, as illustrated in Fig. 1. The height of an oil column in a preferentially oil-wet capillary is proportional to the product of the interfacial tension and the cosine of the contact angle. Buoyancy is an omnipresent driving force for displacement of oil by water. Reduction of interfacial tension and alteration of wettability inside the matrix will reduce the tendency for capillarity to retain the oil. Thus a low-tension process has the process fluids entering the matrix to replace the oil that is leaving by buoyancy ${ }^{4}$, as illustrated in Fig. 3 .

The effect of buoyancy displacing oil from between two parallel surfaces is demonstrated with the system in Fig. 11. A calcite (marble) plate was aged in crude oil at room temperature. It is placed in an optical cell with a plastic film as a spacer to create a $13 \mu \mathrm{m}$ gap between the plate and the front wall of the cell. The glass of the front of the cell has been treated with a dilute solution of hexadecyltrimethylammonium bromide to make the glass preferentially oil-wet. Oil in the gap is not displaced when the cell is filled with brine, Fig. 12(a). The buoyancy forces cannot overcome the capillary entry pressure to displace the oil from the gap. However, when the brine is replaced with $0.05 \%$ CS-330 / $0.3 \mathrm{M}$ $\mathrm{Na}_{2} \mathrm{CO}_{3}$, the displacement of oil is rapid, Fig. 12(b). The alkaline surfactant solution both lowers the interfacial tension and alters the wettability of both the calcite and glass surfaces. Only isolated drops of oil remain after 7 hours.

One qualitative difference between displacement of oil from a gap between parallel surfaces and a porous rock is that the gap has $100 \%$ oil 
saturation while a porous rock has formation brine occupying the pore space along with the oil, Fig. 13. Buoyancy may displace the mobilized oil but the formation brine may form a bank ahead of the alkaline surfactant solution. Dispersive mixing is necessary for the alkaline surfactant solution to penetrate through the bank of formation brine and contact the trapped oil. Also, the alkaline surfactant solution must remain active as it mixes with the formation brine.

\section{Surfactant Formulations}

It was mentioned earlier that nonionic and cationic surfactants have been previously evaluated for wettability alteration in carbonate formations ${ }^{5-13}$. This investigation focuses on the use of anionic surfactants and sodium carbonate. It builds on the previous understanding developed for alkaline surfactant flooding ${ }^{36,37}$. Also, this technology has found many applications during the past decade when it was commonly thought that surfactant flooding was not economical because of the expense of the surfactant ${ }^{38-53}$.

There are a number of reasons for choosing sodium carbonate as the alkali. We mentioned earlier that the carbonate/bicarbonate ion is a potential determining ion for carbonate minerals and thus is able to impart a negative zeta potential to the calcite/brine interface, even at neutral $\mathrm{pH}$. A negative zeta potential is expected to promote water-wetness. Other reasons for choosing sodium carbonate include:

- The moderately high $\mathrm{pH}$ generates natural surfactants from the naphthenic acids in the crude oil by in situ saponification;

- Sodium carbonate suppresses calcium ion concentration;

- Sodium carbonate reduces the extent of ion exchange and mineral dissolution (in sandstones) compared with sodium hydroxide ${ }^{40,54}$;

- Adsorption of anionic surfactants is low with the addition of an alkali, especially with sodium carbonate ${ }^{36,52-56 \text {; }}$

- Carbonate precipitates do not adversely affect permeability as compared to hydroxide and silicates ${ }^{54}$;

- Sodium carbonate is an inexpensive alkali since it is mined as the sodium carbonate - bicarbonate mineral, trona.

The phase behavior of MY3 crude oil and different concentrations of sodium carbonate solution is shown in Fig. 14. The aqueous phase is most turbid at a concentration of $0.1 \mathrm{M}$ and becomes clear at a concentration of $0.2 \mathrm{M}$. Based on an acid number of $0.2 \mathrm{mg} \mathrm{KOH} / \mathrm{g}$, a concentration of $0.003 \mathrm{M} \mathrm{Na}_{2} \mathrm{CO}_{3}$ is required to neutralize the acid to soap and $\mathrm{NaHCO}_{3}$. The $\mathrm{pH}$ of the equilibrated solutions exceeds 10 with a $\mathrm{Na}_{2} \mathrm{CO}_{3}$ concentration of $0.05 \mathrm{M}$. The clear aqueous phase at a concentration of $0.2 \mathrm{M}$ indicates that a Winsor Type II microemulsion has formed at this concentration. This is an oil-continuous microemulsion, or is commonly called as "over-optimum". Thus a concentration of alkali large enough to transport through a reservoir is often over-optimum in electrolyte strength. 
Some crude oil-brine-mica systems, which were water-wet at high $\mathrm{pH}$ and low salinity, became oil-wet at high $\mathrm{pH}$ and high salinity ${ }^{57,58}$. Thus, the over-optimum phase behavior must be avoided if water-wet conditions are desired. Also, overoptimum conditions result in high surfactant retention in conventional surfactant flooding ${ }^{59}$.

The choice of surfactants to use for an alkaline surfactant process for carbonate formation was guided by the experience with sandstone formations but recognizing that adsorption is going to be on the carbonate minerals, calcite and dolomite. Thus internal olefin sulfonates, which are effective for sandstones ${ }^{37}$, were not considered since they are very sensitive to calcium ions. Rather, ethoxylated and propoxylated sulfate surfactants were evaluated ${ }^{60-63}$ because of their known tolerance to divalent ions. Sulfates rather than sulfonates were evaluated because of their greater availability and because the target application is at a low temperature where the sulfate hydrolysis should not be a problem. The surfactants evaluated are identified in Table 2. CS-330 is similar to NEODOL 25-3S, used previously ${ }^{36}$. The propoxylated surfactants are calcium tolerant such that $\mathrm{CaCl}_{2}$ has been used as the electrolyte to achieve optimal salinity ${ }^{63}$.

The phase behavior of the MY3 crude oil with alkaline surfactant solutions as a function of $\mathrm{Na}_{2} \mathrm{CO}_{3}$ concentration with $0.05 \%$ (active material) surfactant is shown in Figs. 15-18. The systems were shaken for 2 days and allowed to equilibrated for 5-7 days. CS-330 is shown in Fig. 15; C12-3PO in Fig. 16; TDA $4 \mathrm{PO}$ in Fig. 17; and ISOFOL14T-4.1PO in Fig. 18. Only $\mathrm{Na}_{2} \mathrm{CO}_{3}$ was used as the electrolyte rather than a mixture of $\mathrm{NaCl}$ and $\mathrm{Na}_{2} \mathrm{CO}_{3}$ to reduce a degree of freedom in the comparisons. The spinning-drop interfacial tensions of the equilibrated (5-19 days) oleic and aqueous phases are shown in Fig. 19. All systems have interfacial tension in the range $10^{-3}-10^{-2} \mathrm{mN} / \mathrm{m}$ for a range of $\mathrm{Na}_{2} \mathrm{CO}_{3}$ concentrations. Nelson et al. ${ }^{36}$ pointed out that the amount of oil relative to the amount of synthetic surfactant is an important parameter since the natural surfactant from the naphthenic acids and the synthetic surfactant have different optimal salinities. This is illustrated by the dependence of the interfacial tension on the water/oil ratio, Fig. 20, since the synthetic surfactant is supplied with the water and the natural surfactant comes from the oil. While each system had ultra-low tension at a water/oil ratio of 1:1, the tension increases with increase in water/oil ratio. This increase is rapid for CS-330 but much less for TDA-4PO. The phase behavior of the systems with increased concentrations of TDA-4PO of $0.2 \%$ (active material) and $1 \%$ are shown in Figs. 21 and 22 . Compared to a concentration of $0.05 \%$, the corresponding phase behavior has moved to higher $\mathrm{Na}_{2} \mathrm{CO}_{3}$ concentrations. The interfacial tensions, shown in Fig. 23, have optimal conditions at higher $\mathrm{Na}_{2} \mathrm{CO}_{3}$ concentrations. Also, the minimum tension is lower with the higher surfactant concentrations. Apparently, the optimal salinity changes to higher electrolyte strength since the ratio of the synthetic surfactant to natural surfactant increases with increasing surfactant concentration. These dependencies must be considered in optimizing a system for oil recovery ${ }^{36,62}$. 


\section{Mixing with formation brine}

Mixing with formation brine has always been an important issue with surfactant flooding, but new considerations are needed because of the presence of sodium carbonate. Hard water cannot be used to prepare the solutions for injection because of precipitation of $\mathrm{CaCO}_{3}$. Also, premature production of injected fluids should be minimized to avoid production well scaling and produced emulsions. Fig. 13 shows that there will be mixing with the formation brine as the alkaline surfactant solution invades the formation matrix. Besides dilution, alkalinity will be lost due to precipitation of divalent ions in the formation brine. The surfactant formulation should be formulated such that the diluted system is active in altering

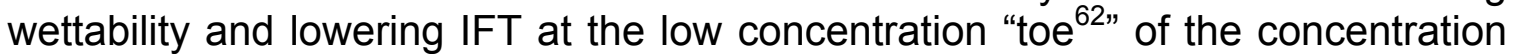
profile illustrated in Fig. 13. This will require evaluating changes in: electrolyte strength, alkalinity and $\mathrm{pH}$, surfactant concentration, and ratio of synthetic/natural surfactants. The small solubility product of calcium carbonate sequesters calcium ion concentration. A small amount of sodium silicate should be considered in the formulation to sequester the magnesium ion concentration ${ }^{37}$.

\section{Alkali consumption and surfactant adsorption}

Alkali consumption is an important issue in sandstones because of ion exchange with clays, dissolution of silicate minerals, mixing with formation brine, and neutralization of the acids in the crude oil. Soluble calcium minerals such as gypsum or anhydrite can contribute to alkali consumption. However, Cheng ${ }^{54}$, found no significant consumption of $\mathrm{Na}_{2} \mathrm{CO}_{3}$ on dolomite. Olsen, et al. ${ }^{38}$, reported 5.8 meq of alkalinity consumed per $\mathrm{kg}$ of carbonate rock with an ASP system using $\mathrm{Na}_{2} \mathrm{CO}_{3}$ and sodium tripolyphospate. Measurement of alkali consumption of the system of interest is needed to determine how much of the electrolyte strength can be accomplished with $\mathrm{NaCl}$ rather than $\mathrm{Na}_{2} \mathrm{CO}_{3}$.

Addition of an alkali significantly reduces surfactant adsorption in sandstones ${ }^{36}$. Al-Hashim, et al. ${ }^{55}$, showed surfactant adsorption on limestone to be decreased in the presence of $1: 1 \quad \mathrm{NaHCO}_{3}: \mathrm{Na}_{2} \mathrm{CO}_{3}$ for low surfactant concentrations.

Surfactant adsorption on powdered calcite without or with sodium carbonate was determined by potentiometric titration with hyamine. The initial surfactant concentration was fixed at either $0.05 \%$ or $0.1 \%$ (active material), while calcite powder were added at varied weight ratios. The equilibrium surfactant concentration was determined by titration. The calcite powder surface area was determined by BET adsorption, and surfactant adsorption density was calculated.

The adsorption of a 1:1 blend of CS-330 and TDA-3PO without or with sodium carbonate is shown in Fig. 24. The adsorption isotherm in the absence of sodium carbonate is similar to a Langmuir adsorption isotherm with a plateau adsorption of about $0.002 \mathrm{mmol} / \mathrm{m}^{2}$. This corresponds to adsorption of 83 $\AA^{2} /$ molecule. This is about one-fourth of the adsorption density of a close-packed monolayer (of $20 \AA^{2} /$ molecule for a linear alkane surfactant.). Addition of $0.3-$ $0.45 \mathrm{M}$ sodium carbonate reduced the adsorption by a factor of 10 to about $2 \times 10^{-}$ ${ }^{4} \mathrm{mmol} / \mathrm{m}^{2}$. 
The adsorption density without and with sodium carbonate was similar for CS-330. However, the apparent adsorption of TDA-3PO with sodium carbonate had abnormal high values with small addition of calcite, Fig. 25. It was observed that solutions of TDA-4PO and $0.3 \mathrm{M}$ sodium carbonate were turbid and light scattering measurements indicated $200-300 \mathrm{~nm}$ aggregates. Apparently the aggregates co-precipitated with the calcite when the latter was separated by centrifugation. The solutions of CS-330 and 1:1 CS-330/TDA-4PO with sodium carbonate were not turbid and did not show abnormal adsorption.

\section{Oil recovery by spontaneous imbibition}

Spontaneous imbibition experiments were conducted with formation brine, stock tank oil, MY3, and core samples of the dolomite formation of the reservoir of interest. The properties of the dolomite core samples and experimental conditions are listed in Table 3 . There was no further extraction or cleaning of the cores. The composition of the formation brine is in Table 4. The initial oil saturation was established by flowing oil with the indicated pressure drop. Some samples were aged 24 hours at $80^{\circ} \mathrm{C}$. Oil recovery by spontaneous imbibition was measured by placing the oil-saturated cores in imbibition cells filled with either formation brine or alkaline surfactant solution, Fig. 26. Not a single drop of oil was recovered by spontaneous imbibition in formation brine during one to two weeks, Fig 26(a). The formation brine was replaced with alkaline surfactant solution and the enhanced oil recovery by spontaneous imbibition was measured. Small drops of oil on the top end face of the core could be observed accumulating, detaching and being collected in the imbibition cell, Fig. 26(b). The appearance of oil on the top face rather than the sides of the core suggests that the displacement was dominated by buoyancy rather than counter-current capillary imbitition. The oil recovery as a function of time is shown in Fig. 27.

Possible factors affecting the difference in oil recovery in Fig. 27 include permeability, initial oil saturation, surfactant formulation, and condition of aging. The surfactant formulation and aging conditions are not the dominant parameters since systems with the greatest and least recovery have the same surfactant formulation and the system aged at $80^{\circ} \mathrm{C}$ has greater recovery than the system aged at room temperature. The effect of difference in permeability can be evaluated by plotting the oil recovery as a function of dimensionless time for gravity dominated recovery.

$$
t_{D g}=\frac{k k_{r o}^{o} \Delta \rho g t}{\left(S_{o i}-S_{o r}\right) \phi \mu_{o} L}
$$

The fractional recovery is expressed as a fraction of recoverable oil, assuming that the remaining oil saturation at the last measured point in Fig. 27 is the residual oil saturation. The experimental results are compared to the one dimensional, gravity drainage analytical solution ${ }^{64,65}$ assuming zero capillary pressure and a relativity permeability exponent of $n=3$. The analytical solution is as follows. 


$$
\begin{aligned}
& E_{R} \equiv \frac{S_{o i}-\bar{S}_{o}}{S_{o i}-S_{o r}} \\
& E_{R}= \begin{cases}t_{D g}, & t<t_{B T} \\
1-\frac{(1-1 / n)}{\left(n t_{D g}\right)^{\frac{1}{n-1}}}, & t>t_{B T}\end{cases} \\
& t_{D g, B T}=1 / n
\end{aligned}
$$

The fractional recovery is plotted as a function of dimensionless time for gravity drainage and compared with the analytical solution in Fig. 28. The recovery expressed in this way accounts for the difference in permeability. The fractional recovery appears to scale as if the rate of recovery of the mobile oil is due to gravity drainage. However, the remaining oil saturation (ROS) appears to be a function of permeability or initial oil saturation, Table 3 . More investigation is needed to determine if permeability or initial oil saturation is indeed the responsible parameter and if so, why. The surfactant and alkali system needs to be optimized to minimize the remaining oil saturation.

The hypothesis that the recovery was dominated by capillary imbibition was examined by plotting the oil recovery as a function of dimensionless time for recovery by spontaneous capillary imbibition ${ }^{66}$ in Fig. 29.

$$
t_{D, P_{c}}=t \sqrt{\frac{k}{\phi}} \frac{\sigma}{\sqrt{\mu_{o} \mu_{w}}} \frac{1}{L_{c}^{2}} .
$$

The interfacial tension in the dimensionless time is a value of $10^{-3} \mathrm{mN} / \mathrm{m}$, which was a typical value for the three systems, Fig. 19. The measured oil recovery occurred faster than that for the very strongly water-wet (VSWW) correlation. This observation implies that either some other mechanism such as gravity was contributing to recovery or capillary imbibition was contributing but the interfacial tensions are different from the assumed value.

If the oil recovery is dominated by buoyancy and each matrix block acts independently, the analytical solution, Eq. (3) can be used to scale-up to different permeability and matrix block size. The time to a given level of recovery will be proportional to the height of the matrix block, $L$, and inversely proportional to permeability, $k$. However, the assumption that the matrix blocks act independently is challenged by the possibility of capillary contact between matrix blocks. Capillary contact between matrix blocks and re-entry of oil into matrix blocks will lengthen the time for oil recovery.

\section{Future work}

The work to date has been to identify the important factors affecting enhanced recovery with alkaline surfactant solution rather than to optimize the system. A practical system will have only enough $\mathrm{Na}_{2} \mathrm{CO}_{3}$ to satisfy the alkali consumption and use $\mathrm{NaCl}$ for the remainder of the electrolyte strength. The frontal advance 
rates of the alkali, surfactant and salinity should be optimized to have mazimize the size of the active region. The process should be designed to be robust to tolerate mixing with the formation brine either in the fractures or in the matrix ${ }^{67}$.

The different surfactants need to be systematically characterized. Fundamental questions remain about mixtures of dissimilar surfactants, i.e., naphthenic soap and synthetic surfactant.

Measurement of interfacial tensions between the upper and lower phases is problematic because the microemulsion in a three-phase system is segregating to a very thin middle layer with time. The loss of microemulsion from the measured excess aqueous and oil phases results in increasing interfacial tension values.

One alkaline surfactant system shown here altered a calcite plate that was aged at room temperature to preferentially water-wet conditions. However, the system that was aged at $80^{\circ} \mathrm{C}$ only altered to intermediate-wet $\left(\sim 90^{\circ}\right.$ contact angle). The mechanisms governing the wettability alteration ${ }^{57,68}$ and methods to make the elevated aging temperature system more water-wet will be sought.

The long-term stability of surfactant formulations at the condition of application should be evaluated. Talley ${ }^{69}$ shows that ethoxylated sulfates, as those shown here are unstable at low $\mathrm{pH}$ and high temperatures. They were more stable at neutral and high $\mathrm{pH}$ provided a significant concentration of calcium ions was not present. $\mathrm{Na}_{2} \mathrm{CO}_{3}$ should suppress the calcium ion concentration in the alkaline surfactant systems discussed here.

The spontaneous imbibition experiments shown were in small cores. The controlling displacement mechanism needs to be identified and be scaled to the rate of displacement from matrix blocks of dimensions typical of actual reservoirs.

The scope of the work discussed here is limited to a single matrix block. Sweep efficiency is an equally important factor in oil recovery, especially in fractured formations. Fracture systems generally have a broad distribution of fracture widths. The wider fractures will act as thief zones for the injected fluid and little of the injected fluid will reach the narrower fractures. Favorable mobility ratio displacement aids in the distribution of injected fluids in heterogeneous systems. Polymer has commonly been used for mobility control of surfactant flooding processes. However, polymer will also retard the invasion of the surfactant solution into the matrix. An alternative process of mobility control for surfactant flooding is foam ${ }^{53,70}$. Foam mobility control has been field demonstrated for aquifer remediation ${ }^{71,72}$ and since then, applied to full-scale expansions.

\section{Conclusions}

1. Crude oils used for interfacial research should be screened for contamination. Crude oil/brine interfacial tension less than $10 \mathrm{mN} / \mathrm{m}$ is an indication of contamination. 
2. Calcite, which is normally positively charged at neutral $\mathrm{pH}$, can be made negatively charged through the presence of $\mathrm{NaHCO}_{3} / \mathrm{Na}_{2} \mathrm{CO}_{3}$ in the brine.

3. The wettability of crude oil/brine on a calcite plate is a function of aging time. After 24 hours, the plate was oil-wet regardless of whether the aging in crude oil was at room temperature or $80^{\circ} \mathrm{C}$. The degree of wettability alteration with alkaline surfactant systems observed here ranged from preferentially water-wet to intermediate-wet and was a function of the prior aging temperature in crude oil.

4. Oil is retained in oil-wet pores by capillarity. Oil displacement can occur by buoyancy if an alkaline surfactant solution reduces interfacial tension and/or alters wettability to more water-wet conditions. The displacement could also be assisted by capillarity if the contact angle is less than $90^{\circ}$.

5. Oil recovery from oil-wet dolomite cores has been demonstrated by spontaneous imbibition with an alkaline anionic surfactant solution.

\section{Acknowledgment}

The authors acknowledge Maura Puerto and Clarence Miller for their advice and assistance; Larry Britton and Upali Weerasooriya for the surfactants, and Jill Buckley for the crude oil analysis. Hung-Lung Chen and Marathon Oil Company are acknowledged for the crude oil, core samples and the imbibition apparatus. The financial support of the Consortium on Processes in Porous Media and the U.S. DOE Awards \#DE-AC26-99BC15205 and \#DE-FC26-03NT15406 are gratefully acknowledged.

\section{Nomenclature}

$\begin{array}{lll}E_{R} & = & \text { recovery efficiency } \\ g & = & \text { acceleration of gravity, } \mathrm{m} / \mathrm{s}^{2} \\ I F T & = & \text { interfacial tension, } \mathrm{mN} / \mathrm{m} \\ k & = & \text { permeability, } \mathrm{m}^{2}(\mathrm{md}) \\ k_{\text {ro }}^{o} & = & \text { relative permeability } \\ L & = & \text { length, } \mathrm{m} \\ n & = & \text { oil relative permeability exponent } \\ N_{B} & = & \text { Bond number } \\ R O S & = & \text { remaining oil saturation } \\ S_{\mathrm{Oi}} & = & \text { initial oil saturation } \\ S_{\mathrm{or}} & =\quad \text { residual oil saturation } \\ t & =\quad \text { time, } \mathrm{s} \\ t_{\mathrm{Dg}} & =\quad \text { dimensionless time for gravity drainage } \\ t_{\mathrm{D}, \mathrm{PC}}=\text { dimensionless time for capillary imbibition }\end{array}$




$$
\begin{array}{rll}
\mu_{0} & = & \text { oil viscosity, } \mathrm{Pa} \cdot \mathrm{s}(\mathrm{cp}) \\
\mu_{\mathrm{w}} & = & \text { water viscosity, } \mathrm{Pa} \cdot \mathrm{s}(\mathrm{cp}) \\
\phi & = & \text { porosity } \\
\sigma & = & \text { interfacial tension, } \mathrm{N} / \mathrm{m} \\
\Delta \rho & = & \text { density difference, } \mathrm{kg} / \mathrm{m}^{3}
\end{array}
$$

\section{References}

1. Wardlaw, N.C.: "Factors Affecting Oil Recovery from Carbonate Reservoirs and Prediction of Recovery," in Carbonate Reservoir Characterization: A Geologic-Engineering Analysis, Part II, Chilingarian, G.V., Mazzullo, S.J., and Rieke, H.H., ed., Elsevier, New York, (1996) 867.

2. Van Golf-Racht, T.D.: "Naturally-Fractured Carbonate Reservoirs," in Carbonate Reservoir Characterization: A Geologic-Engineering Analysis, Part II, Chilingarian, G.V., Mazzullo, S.J., and Rieke, H.H., ed., Elsevier, New York, (1996) 683.

3. Morrow, N.R. and Mason, G.: "Recovery of oil by spontaneous imbibition," Current Opinion in Colloid \& Interface Science, (2001) 6, 321.

4. Schechter, D.S., Zhou, D., and Orr, F.M., Jr.: "Low IFT drainage and imbibition," J. Pet. Sci. \& Eng., (1994) 11283.

5. Miller, J. and Austad, T.: "Chemical flooding of oil reservoirs. 6. Evaluation of the mechanisms for oil expulsion by spontaneous imbibition of brine with and without surfactant in water-wet, low permeability, chalk material," Colloids and Surfaces A: Physicochemical and Engineering Aspects, (Aug 10, 1996) 113, No. 3269.

6. Miller, J. and Austad, T.: "Chemical flooding of oil reservoirs. 7. Oil expulsion by spontaneous imbibition of brine with and without surfactant in mixed-wet, low permeability chalk material," Colloids and Surfaces A: Physicochemical and Engineering Aspects, (Oct. 5, 1996) 117, No. 1-2 109.

7. Austad, T., Matre, B., Milter, J., Saevaried, A., and Oyno, L.: "Chemical flooding of oil reservoirs. 8. Spontaneous oil expulsion from oil- and waterwet low permeability caulk material by imbibition of aqueous surfactant solutions," Colloids and Surfaces A: Physicochemical and Engineering Aspects, (June 15, 1998) 137, No. 1-3 117.

8. Austad, T. and Milter, J.: "Spontaneous imbibition of water into low permeability chalk at different wettabilities using surfactants," Proceedings - SPE International Symposium on Oilfield Chemistry, (1997) 257.

9. Standnes, D.C. and Austad, T.: "Wettability alteration in chalk 1. Preparation of core material and oil properties," J. Pet. Sci. Eng., (2000) 28, 111. 
10. Standnes, D.C. and Austad, T.: "Wettability alteration in chalk 2. Mechanism for wettability alteration from oil-wet to water-wet using surfactants," J. Pet. Sci. Eng., (2000) 28, 123.

11. Standnes, D.C., Nogaret, L.A.D., Chen, H.-L., and Austad, T.: "An evaluation of spontaneous imbibition of water into oil-wet reservoir cores using a nonionic and a cationic surfactant," Energy and Fuels, 16, No. 6 (Nov./Dec. 2002) 1557.

12. Chen, H.L., Lucas, L.R., Nogartet, L.A.D., Yang, H.D., and Kenyon, D.E.: "Laboratory Monitoring of Surfactant Imbibition Using Computerized Tomography," SPE 59006 presented at the 2000 International Petroleum Conference and Exhibition, Villahermosa, Mexico (1-3 February 2000).

13. Spinler, E.A., Zornes, D.R., Tobola, D.P., and Moradi-Araghi, A.: "Enhancement of Oil Recovery Using a Low Concentration of Surfactant to Improve Spontaneous and Forced Imbibition in Chalk," SPE 59290 presented at the 2000 SPE/DOE Improved Oil Recovery Symp., Tulsa, OK (3-5 April 2000).

14. Treiber, L.E., Archer, D.L., and Owens, W.W.: "A Laboratory Evaluation of the Wettability of Fifty Oil-Producing Reservoirs," SPEJ (December, 1972) 531.

15. Schneider, F. N. and Owens, W. W.: "Relative Permeability Studies of Gas-Water Flow Following Solvent Injection in Carbonate Rocks," SPEJ (February 1976) 23.

16. Anderson, W. G.: "Wettability Literature Survey-Part 1: Rock/Oil/Brine Interactions and the Effects of Core Handling in Wettability," JPT (October 1986) 1125.

17. Chilingar, G. V. and Yen, T. F.: "Some Notes on Wettability and Relative Permeabilities of Carbonate Reservoir Rocks, II," Energy Sources, Vol. 7, No. 1 (1983) 67.

18. Lichaa, P. M., Alpustun, H., Abdul, J. H., Nofal, W. A. and Fuseni, A. B.: "Wettability Evaluation of a Carbonate Reservoir Rock," in Advances in Core Evaluation III, Reservoir Management, Worthington, P. F. and Chardaire-Riviere, C., ed. (1993) Gordan \& Breach, 327.

19. Al-Hadhrami, H. S. and Blunt, M. J.: "Thermal Induced Wettability Alteration to Improve Oil Recovery in Fractured Reservoirs," SPE RE\&E (June 2001) 179.

20. Freedman, R., Heaton, N., Flaum, M., Hirasaki, G.J., Flaum, C. and Hurlimann, M.: "Wettability, Saturation, and Viscosity from NMR Measurements," SPEJ, (December 2003), 317.

21. Dubey, S.T. and Doe, P.H.: "Base Number and Wetting Properties of Crude Oils," SPERE (August, 1993) 195. 
22. Hirasaki, G.J.: "Wettability: Fundamentals and Surface Forces," SPEFE (June, 1991) 217.

23. Buckley, J.S., Takamura, K., and Morrow, N.R.: "Influence of Electrical Surface Charges on the Wetting Properties of Crude Oils," SPERE (August, 1989) 332.

24. Douglas, H.W. and Walker, R.A.: "The Electrokinetic Behavior of Iceland Spar Against Aqueous Electrolyte Solutions," Trans. Faraday Soc. (1950), 559.

25. Somasundaran, P. and Agar, G.E.: "The Zero Point of Charge of Calcite," J.C.I.S., (1967) 24, 433.

26. Smallwood, P.V.: "Some Aspects of the Surface Chemistry of Calcite and Aragonite; Part I: An Electrokinetic Study," Col. \& Pol. Sci. (1977), 255, 881.

27. Siffert, B and Fimbel, P.: "A Study of the Parameters Affecting the Sign and Intensity of the Electrokinetic Potential of Calcite," Collect. Colloq. Semin., I.F.P. (1985), 42, 187.

28. Thompson, D.W. and Pownall, P.G.: "Surface Electrical Properties of Calcite," J.C.I.S. (August 1989) 131, 74.

29. Moulin, P. and Roques, H.: "Zeta potential measurements of calcium carbonate," J.C.I.S. (2003) 261, 115.

30. Anderson, J.B., El-Mofty, S.E., and Somasundaran, P.: "Using Electrophororesis for Determination the Mechanism of Amine, Sulfate and Oleate Adsorption on Calcite," Colloids \& Surfaces (1991) 55, 365.

31. Somasundaran, P.: "Adsorption of Starch and Oleate and Interaction Between Them on Calcite in Aqueous Solutions," J.C.I.S. (1969) 31, 557.

32. Morrow, N.R., Cram, P.J., and McCaffery, F.G.: " Displacement Studies in Dolomite with Wettability Control by Octanoic Acid," SPEJ (August, 1973) 221.

33. Hansen, G, Hamouda, A.A., and Denoyel, R.: "The effect of pressure on contact angles and wettability in the mica/water/n-decane system and the calcite+stearic acid/water/n-decane system," Colloids and Surfaces A: Phtsicochemical and Engineering Aspects, (2000), 172, 7.

34. Hartland, S. and Hartley, R.W.: Axisymmetric Fluid-Liquid Interfaces, Elsevier, New York (1976).

35. Finn, R.: Equilibrium Capillary Surfaces, Springer-Verlag, New York, 1986.

36. Nelson, R.C., Lawson, J.B., Thigpen, D.R., and Stegemeier, G.L.: (1984) "Cosurfactant-Enhanced Alkaline Flooding," SPE/DOE 12672 presented at the SPE/DOE Fourth Symp. EOR, Tulsa, OK, April 15-18.

37. Falls, A. H., Thigpen, D. R., Nelson, R. C., Ciaston, J. W., Lawson, J. B., Good, P. A., Ueber, R. C., and Shahin, G. T.: "A Field Test of 
Cosurfactant-Enhanced Alkaline Flooding," SPE/DOE 24117, paper prepared for presentation at the SPE/DOE Eighth Symposium on Enhanced Oil Recovery (April 22-24, 1992) Tulsa, OK.

38. Olsen, D.K., Hicks, M.D., Hurd, B.G., Sinnokrot, and Sweigart, C.N.: "Design of a Novel Flooding System for an Oil-Wet Central Texas Carbonate Reservoir," SPE/DOE 20224 presented at the SPE/DOE Seventh EOR Symp., Tulsa, OK (22-25 April, 1990).

39. Clark, S. R., Pitts, M. J., and Smith, S. M.: "Design and Application of an Alakaline-Surfactant-Polymer Recovery System for the West Kiehl Field," SPE Advanced Technology Series, 1, No. 1 (1993) 172.

40. Baviere, M., Glenat, P., Plazanet, V., and Labrid, J.: "Improved EOR by Use of Chemicals in Combination," SPERE (August, 1995) 187.

41. Gao, S., Li, H., and Li, H.: "Laboratory Investigation of Combination of Alkali/Surfactant/Polymer Technology for Daqing EOR," SPE Reservoir Engineering, (August 1995) 195.

42. Gao, S., Li, H., Yang, Z., Pitts, M. J., Surkalo, H., and Wyatt, K.: "AlkalineSurfactant-Polymer Pilot Performance of the West Central Saetu, Daqing Oil Field," SPE/DOE 35383, paper prepared for presentation the 1996 SPE/DOE Tenth Symposium on Improved Oil Recovery (April 21-24, 1996) Tulsa, OK.

43. Gu, H., Yang, R., Guo, S., Guan, W., Yue, X., and Pan, Q.: Study on Reservoir Engineering: ASP Flooding Pilot Test in Karamay Oilfield," SPE 50918, paper prepared for presentation at the 1998 SPE International Conference and Exhibition (November 2-6, 1998) Beijing, China.

44. French, T.R. and Burchfield, T.E.: Design and Optimization of Alkaline Flooding Formulations, "SPE/DOE 20238 presented at the SPE/DOE Seventh Symp. On EOR, Tulsa, OK (April 22-25, 1990)

45. Meyers, J. J., Pitts, M. J., and Wyatt, K.: "Alkaline-Surfactant-Polymer Flood of the West Kiehl, Minnelusa Unit," SPE/DOE 24144, paper prepared for presentation at the SPE/DOE Eighth Symposium of Enhanced Oil Recovery (April 22-24, 1992) Tulsa, OK.

46. Qiao, Q., Gu, H., Li D., and Dong, L.: "The Pilot Test of ASP Combination Flooding in Karamay Oil Field," SPE 64726, paper prepared for presentation at the SPE International Oil and Gas Conference and Exhibition in China (November 7-10, 2000) Beijing, China.

47. Qu, Z., Zhang, Y., Zhang, X., and Dai, J.: A Successful ASP flooding Pilot in Gudong Oil Field," SPE 39613, paper prepared for presentation at the 1998 SPE/DOE Improved Oil Recovery Symposium (April 19-22, 1998) Tulsa, OK.

48. Surkalo, H.: "Enhanced Alkaline Flooding," SPE 19896, SPE Technology Today Series (January 1990), JPT. 
49. Tong, Z., Yang, C., Wu, G., Yuan, H., Yu, L., and Tian, G.: "Study of Microscopic Flooding Mechanism of Surfactant/Alkali/Polymer," SPE 39662, paper prepared for presentation at the 1998 SPE/DOE Improved Oil Recovery Symposium (April 19-22, 1998) Tulsa, OK.

50. Vargo, J., Turner, J., Vergnani, B., Pitts, M. J., Wyatt, K., Surkalo, H., and Patterson, D.: "Alkaline-Surfactant-Polymer Flooding of the Cambridge Minnelusa Field," SPE Reservoir Eval. \& Eng. (December 2000), 3, No. 6, 552.

51. Wang, D., Zhang, Z., Cheng, J., Yang, J., Gao, S., and Li, L.: "Pilot Tests of Alkaline/Surfactant/Polymer Flooding in Daqing Oil Field," SPERE (November, 1997) 229.

52. Wang, C., Wang, B., Cao, X., and Li, H.: "Application and Design of Alkaline-Surfactant-Polymer System to Close Well Spacing Pilot Gudong Oilfield," SPE 38321, paper prepared for presentation at the 1997 SPE Western Regional Meeting (June 25-27) Long Beach, CA.

53. Zhang, Y., Yue, X., Dong, J., and Yu, L.: "New and Effective Foam Flooding to Recover Oil in Heterogeneous Reservoir," SPE 59367, paper prepared for presentation at the 2000 SPE/DOE Improved Oil Recovery Symposium (April 3-5, 2000) Tulsa, OK.

54. Cheng, K. H.: "Chemical consumption during alkaline flooding: a comparative evaluation," paper 14944 presented at the SPE/DOE Fifth Symposium on Enhanced Oil Recovery, Tulsa, OK. (1986)

55. Al-Hashim, H. S., Obiora, V., Al-Yousef, H. Y., Fernandez, and F. Nofal, W.: "Alkaline surfactant polymer formulation for Saudi Arabian carbonate reservoirs," paper 35353 presented at SPE/DOE Tenth Symposium on Improved Oil Recovery, Tulsa, OK. (1996).

56. Krumrine, P. H., Campbell, T. C., and Falcone, J. S. Jr.: "Surfactant flooding 1: the effect of alkaline additives on IFT, surfactant adsorption, and recovery efficiency," paper 8998 presented at SPE Fifth International Symposium on Oilfield and Geothermal Chemistry, Stanford, CA, (1980).

57. Israelachvili, J. and Drummond, C., "Fundamental Studies of Oil-SurfaceWater Interactions and Its Relationship to Wettability," The $5^{\text {th }}$ International Symposium on Evaluation of Reservoir Wettability and its effect on oil recovery, Trondheim, Norway, (22-24 June 1998).

58. Yang, S.-Y., Mechanisms of Wettability for Crude Oil/Brine/Mica System, Ph.D. thesis, Rice University, Houston, TX. (2000).

59. Glover, C.J., Puerto, M.C., Maerker, J.M., and Sandvik, E.L.:, "Surfactant Phase Behavior and Retention in Porous Media," SPEJ, (June, 1979) 183.

60. Gale, W.W. Puerto, M.C., Ashcraft, T.L., Saunders, R.K., and Reed, R.L.: "Propoxylated Ethoxylated Surfactants and Method of Recovering Oil Therewith," U.S. Patent 4,293,428 (October 6, 1981). 
61. Osterloh, W.T. and Jante, Jr., M.J.: "Surfactant Polymer Flooding with Anionic PO/EO Surfactant Microemulsions Containing Polyethylene Glycol Additives," SPE/DOE paper 24151 presented at the Eighth Symp. On EOR, Tulsa, OK (April 22-24, 1992).

62. Wellington, S.L. and Richardson, E.A.: "Low Surfactant Concentration Enhanced Waterflooding," SPE 30748 paper presented at the SPE ATCE, Dallas, TX (22-25 October, 1995).

63. Aoudia, M., Wade, W.H., and Weerasooriya, V.: "Optimum Microemulsions Formulated with Propoxylated Guerbet Alcohol and Propoxylated Tridecyl Alcohol Sodium Sulfates," J. Dispersion Sci. Tech., 16, No. 2 (1995) 115.

64. Richardson, J.G. and Blackwell, R.J.: "Use of Simple Mathematical Models to Predict Reservoir Behavior," JPT (Sept. 1971) 1145; Trans., AIME, 251.

65. Hagoort, J.: "Oil Recovery by Gravity Drainage," SPEJ (1980) 139.

66. Xie, X. and Morrow, N.R.: "Oil Recovery by Spontaneous Imbibition from Weakly Water-Wet Rocks," Petrophysics, Vol. 42, No. 4 (July-August, 2001), 313.

67. Hirasaki, G.J., van Domselaar, H.R., and Nelson, R.C. "Evaluation of the Salinity Gradient Concept in Surfactant Flooding", Soc. Pet. Eng. J. (June 1983), 486.

68. Reed, R.L. and Healy, R.N.: "Contact Angles for Equilibrated Microemulsion Systems," SPE 8262 presented at the $54^{\text {th }}$ SPE ATCE, Las Vagas, NV (Sept. 23-26, 1979).

69. Talley, L.D.: "Hydrolytic Stability of Alkylethoxy Sulfates," SPE/DOE 14912 presented at the SPE/DOE Fifth Symp. On EOR, Tulsa, OK (April 20-23, 1986).

70. Lawson, J.B. and Reisberg, J.: "Alternate Slugs of Gas and Dilute Surfactant for Mobility Control During Chemical Flooding," SPE 8839 presented at the First Joint SPE/DOE Symp. On EOR, Tulsa, OK (April 20-23, 1980).

71. Hirasaki, G.J., Miller, C.A., Szafranski, R., Tanzil, D., Lawson, J.B., Meinardus, H., Londergan, J.T., Jackson, R.E., Pope, G.A., and Wade, W.H.: "Field Demonstration of the Surfactant/Foam Process for Aquifer Remediation," SPE 39292 presented at the 1997 SPE ATCE, San Antonio (5-8 October 1997).

72. Hirasaki, G. J. Jackson, R. E. Jin, M. Lawson, J. B. Londergan, J. Meinardus, H. Miller, C. A. Pope, G. A. Szafranski, R. and Tanzil, D.: "Field Demonstration of the Surfactant/Foam Process for Remediation of a Heterogeneous Aquifer Contaminated with DNAPL," NAPL Removal: Surfactants, Foams, and Microemulsions, S. Fiorenza, C. A. Miller, C. L. Oubre, and C. H. Ward, ed., Lewis Publishers (2000) 1. 
Table 1 Crude oil properties (Jill Buckley, private communication)

\begin{tabular}{|c|c|c|c|c|c|c|c|c|c|c|c|c|}
\hline Oil ID & ${ }^{\circ} \mathrm{API}$ & $\mathrm{RI} @ 20^{\circ} \mathrm{C}$ & $\rho @ 20^{\circ} \mathrm{C}$ & $\begin{array}{c}\text { Acid\# } \\
\text { mgKOH } \\
/ \mathrm{g} \\
\end{array}$ & \begin{tabular}{|c} 
Base \# \\
$\mathrm{mgKOH}$ \\
$/ \mathrm{g}$
\end{tabular} & $\begin{array}{l}\text { IEP } \\
\mathrm{pH}\end{array}$ & $\mathrm{B} / \mathrm{A}$ & $\begin{array}{c}\text { Sat. } \\
\%\end{array}$ & $\begin{array}{c}\text { Arom. } \\
\%\end{array}$ & $\begin{array}{c}\text { Resins } \\
\%\end{array}$ & $\begin{array}{c}\text { Asph. } \\
\%\end{array}$ & Visc.(cp) \\
\hline MY1 & 27.2 & 1.4979 & 0.8887 & 0.50 & 1.17 & 3.2 & 2.34 & 64.02 & 24.59 & 9.67 & 1.71 & 22.6 \\
\hline MY2 & 28.9 & 1.4941 & 0.8789 & 0.17 & 1.16 & 3.7 & 6.82 & 62.52 & 23.72 & 12.68 & 1.08 & 18.1 \\
\hline MY3 & 28.2 & 1.4955 & 0.8830 & 0.20 & 1.17 & 3.3 & 0.00 & 61.86 & 24.83 & 12.22 & 1.09 & 19.1 \\
\hline IY4 & 28.4 & 1.4943 & 0.8818 & 0.22 & 1.23 & 3.4 & 5.59 & 65.28 & 23.69 & 9.94 & 1.10 & 18.8 \\
\hline
\end{tabular}

Table 2 Surfactant identification

\begin{tabular}{|l|l|}
\hline Trade name & Structural name \\
\hline CS-330 & Sodium dodecyl 3EO sulfate \\
\hline C12-3PO & Sodium dodecyl(Guerbet) 3PO sulfate ${ }^{63}$ \\
\hline TDA-4PO & Ammonium iso-tridecyl 4PO sulfate \\
\hline ISOFOL14T-4.1PO & Sodium tetradecyl(Guerbet) 4PO sulfate \\
\hline
\end{tabular}


Table 3 Core properties and recovery

\begin{tabular}{|l|l|l|l|}
\hline Property & Core A & Core B & Core C \\
\hline Diameter, inch & 1.5 & 1.5 & 1.5 \\
\hline Length, inch & 3.5 & 3 & 3 \\
\hline Porosity, \% & 20 & 24 & 24 \\
\hline Permeability, md & 90 & 122 & 40 \\
\hline Brine ${ }^{*}$ & Brine 1 & Brine 2 & Brine 2 \\
\hline Crude oil & MY3 & MY3 & MY3 \\
\hline Pressure drop, psi & 250 & 130 & 550 \\
\hline Initial oil saturation & 0.71 & 0.68 & 0.82 \\
\hline Aging & $80{ }^{\circ} \mathrm{C}, 24 \mathrm{hr}$ & $80^{\circ} \mathrm{C}, 24 \mathrm{hr}$ & None \\
\hline Time in brine, days & 9 & 8 & 14 \\
\hline Recovery in brine, \%OOIP & 0 & 0 & 0 \\
\hline Surfactant & TDA-4PO & $\begin{array}{l}\text { CS-330+ } \\
\text { TDA-4PO }\end{array}$ & $\begin{array}{l}\text { CS-330+ } \\
\text { TDA-4PO }\end{array}$ \\
\hline Surf. conc., wt\% & & 0.025 & 0.025 \\
& 0.05 & +0.025 & +0.025 \\
\hline Na $_{2} \mathrm{CO}_{3}, \mathrm{M}$ & & 0.3 & 0.3 \\
\hline Time in surf., days & 381 & 138 & 132 \\
\hline Recovery in surf, \%OOIP & 28 & 44 & 14 \\
\hline ROS & 0.51 & 0.38 & 0.70 \\
\hline & 0.3 & & \\
\hline
\end{tabular}


Table 4 Formation brine composition

\begin{tabular}{|c|c|c|}
\hline Salts & Brine 1, gram/liter & Brine 2, gram/liter \\
\hline $\mathrm{NaCl}$ & 24.497 & 5.815 \\
\hline $\mathrm{KCl}$ & 0.275 & 0.000 \\
\hline $\mathrm{CaCl}_{2} .2 \mathrm{H}_{2} \mathrm{O}$ & 5.502 & 2.942 \\
\hline $\mathrm{MgCl}_{2} \cdot 6 \mathrm{H}_{2} \mathrm{O}$ & 7.984 & 2.032 \\
\hline $\mathrm{Na}_{2} \mathrm{SO}_{4}$ & 0.606 & 0.237 \\
\hline $\mathrm{Fe}\left(\mathrm{NH}_{4}\right)_{2}\left(\mathrm{SO}_{4}\right)_{2} \cdot 6 \mathrm{H}_{2} \mathrm{O}$ & 0.000 & 0.007 \\
\hline
\end{tabular}




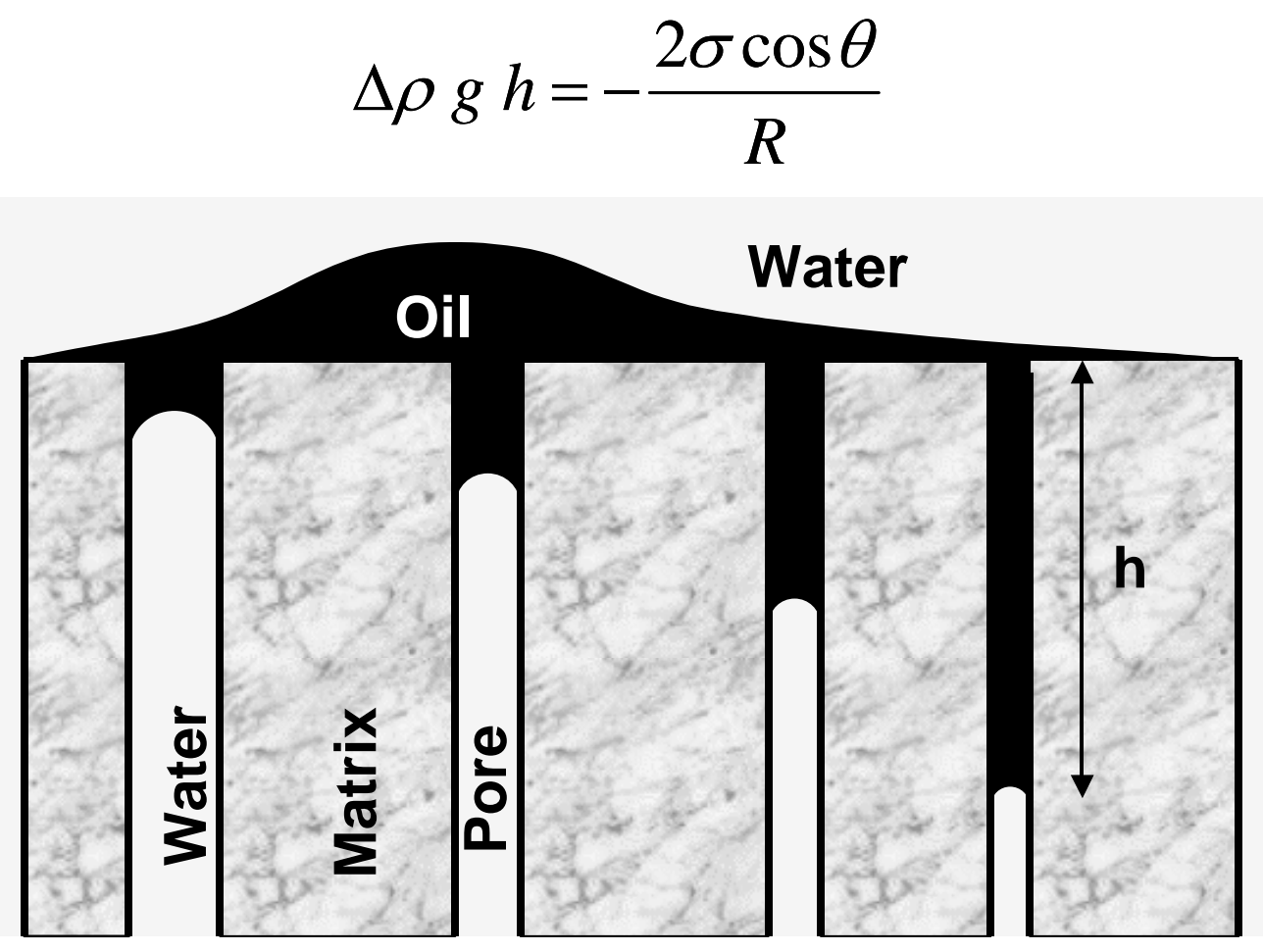

Fig. 1 The height of the retained oil in oil-wet matrix pores is a function of the pore radius, interfacial tension, and contact angle.
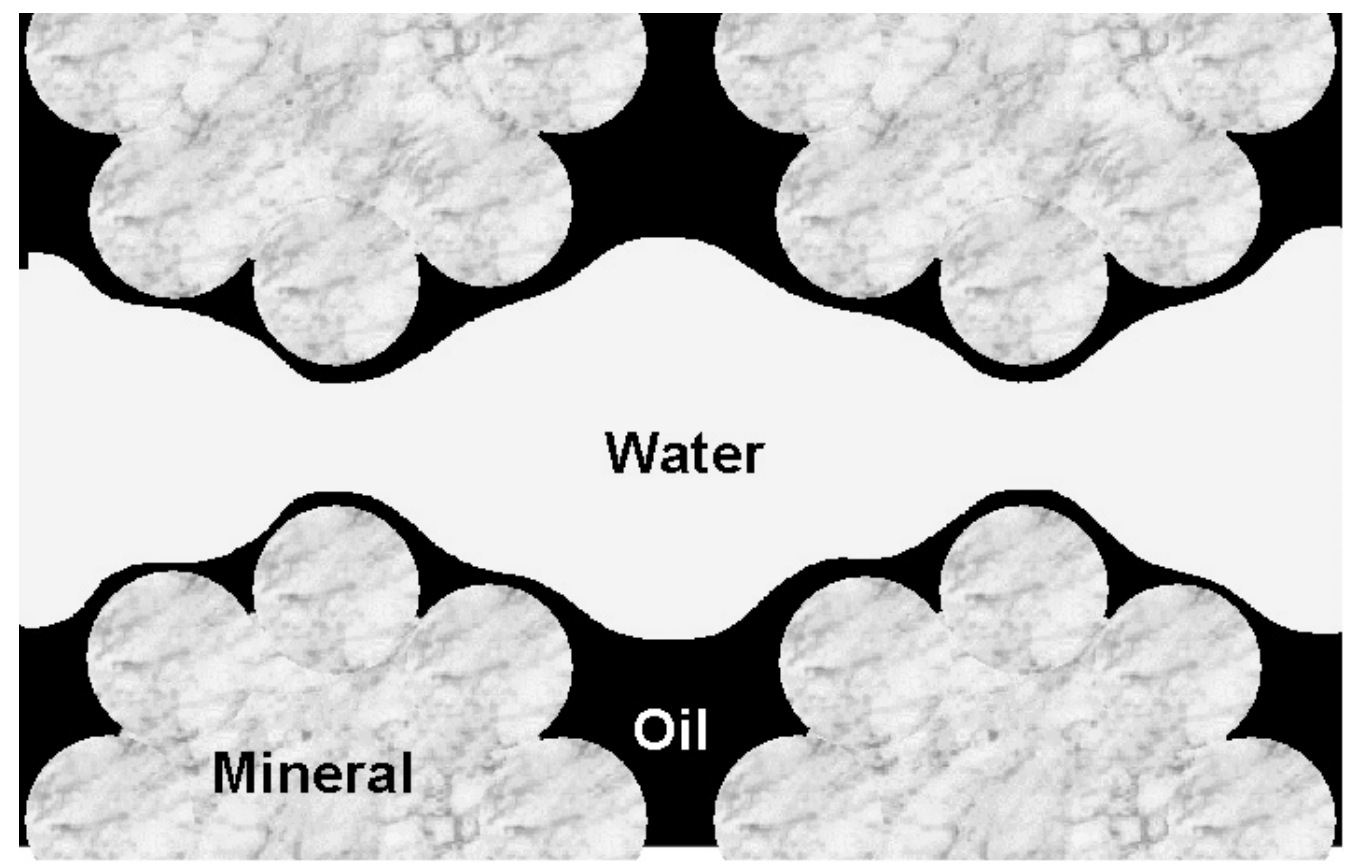

Fig. 2 Oil is trapped by surface trapping in oil-wet and small pores of oil-wet systems. 


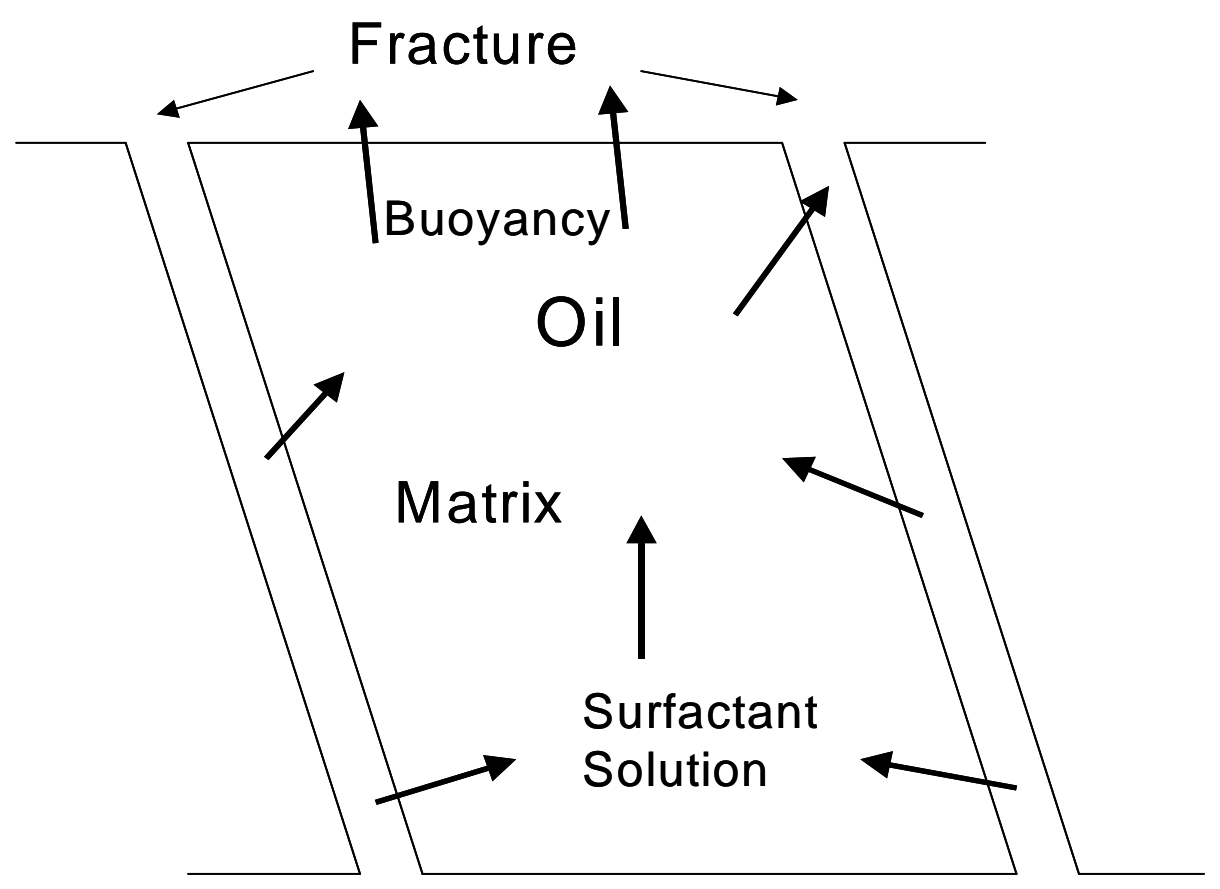

Fig. 3 Spontaneous imbibition of surfactant solution from the fracture system into the matrix occurs to replace the oil that flows out of the matrix by buoyancy.

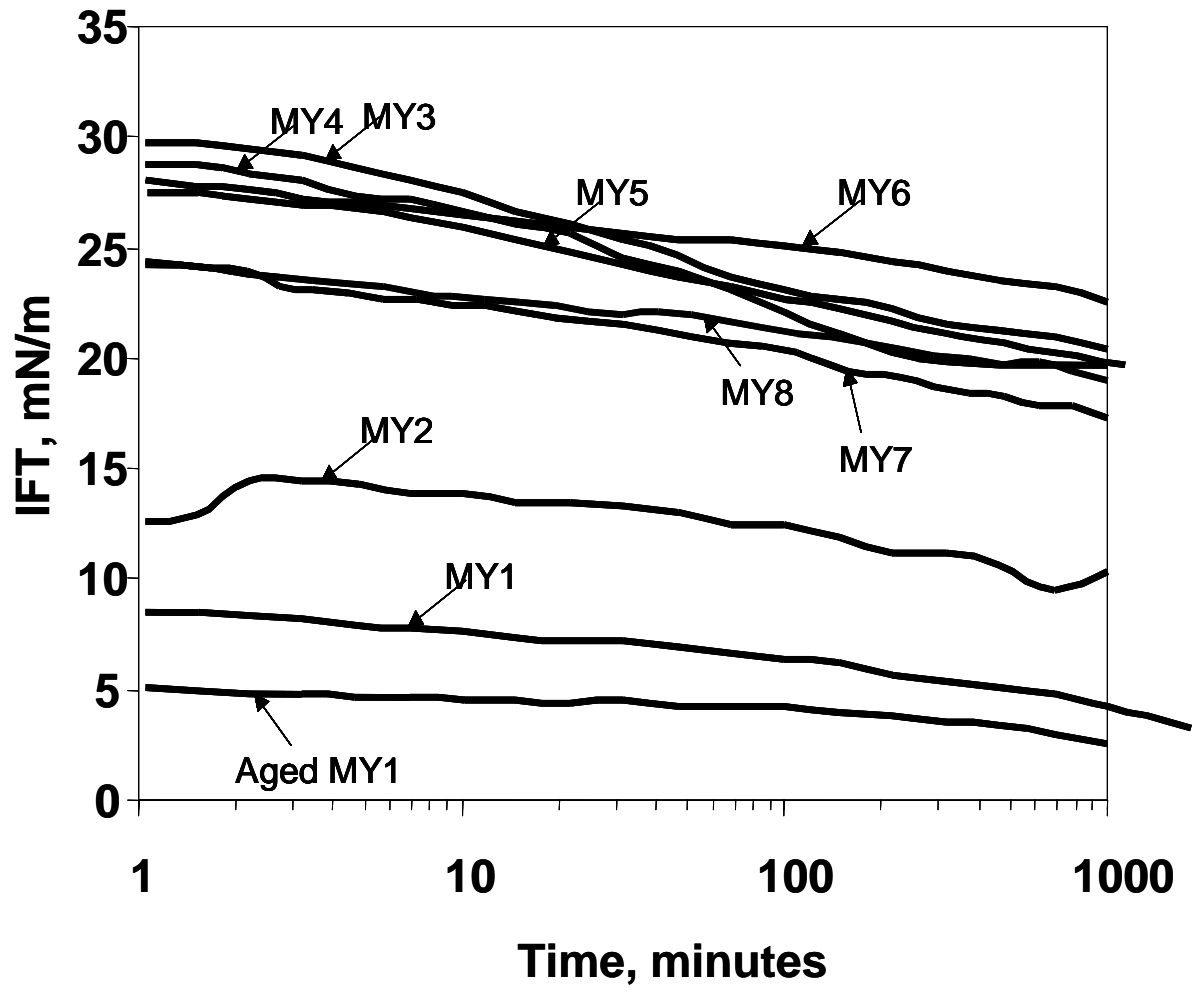

Fig. 4 Crude oil/brine IFT is an indication of whether or not the crude oil is contaminated with surface-active material. 


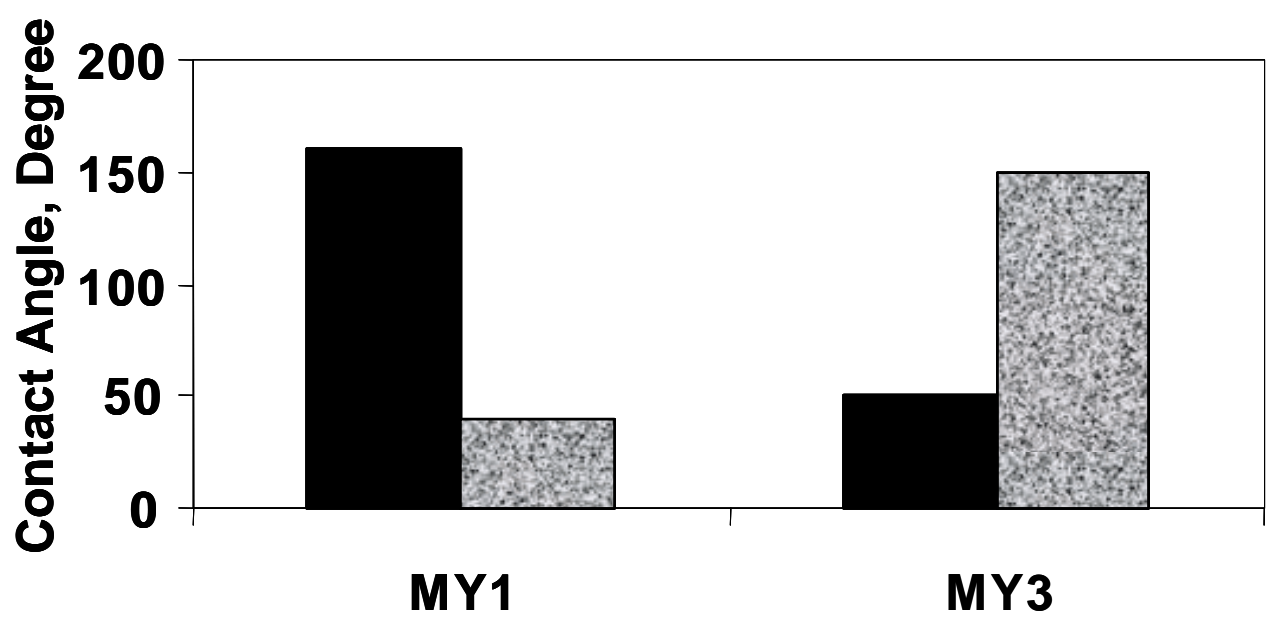

Crude Oils

Advancing angles on marble Advancing angles on glass

Fig. 5 Water advancing contact angles of MY1 and MY3 crude oils on calcite and glass with 5-10 minutes aging time.

Aged at room temperature

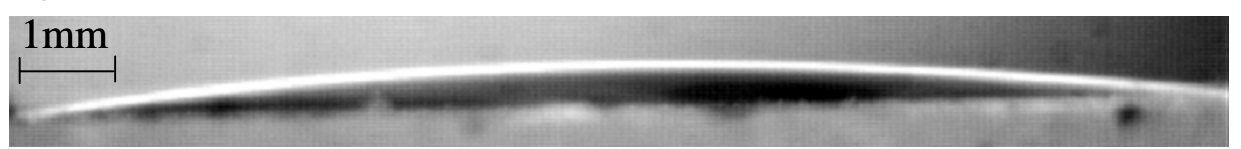

(a)

Aged at $80^{\circ} \mathrm{C}$

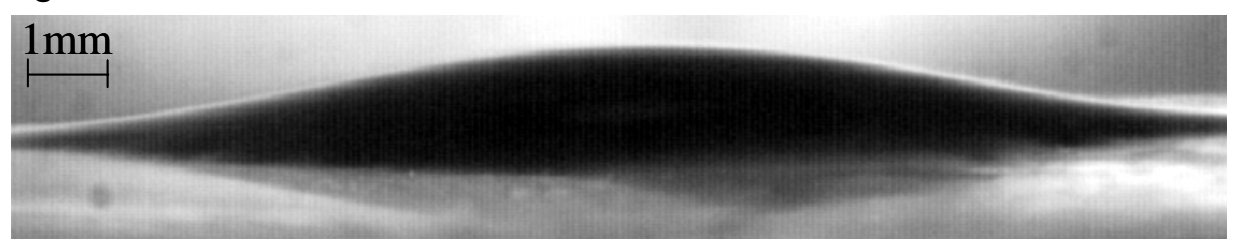

(b)

Fig. 6 Water advancing contact angle of MY3 crude oil in $0.1 \mathrm{M} \mathrm{NaCl}$ brine after aging for 24 hours either at room temperature or $80^{\circ} \mathrm{C}$. 


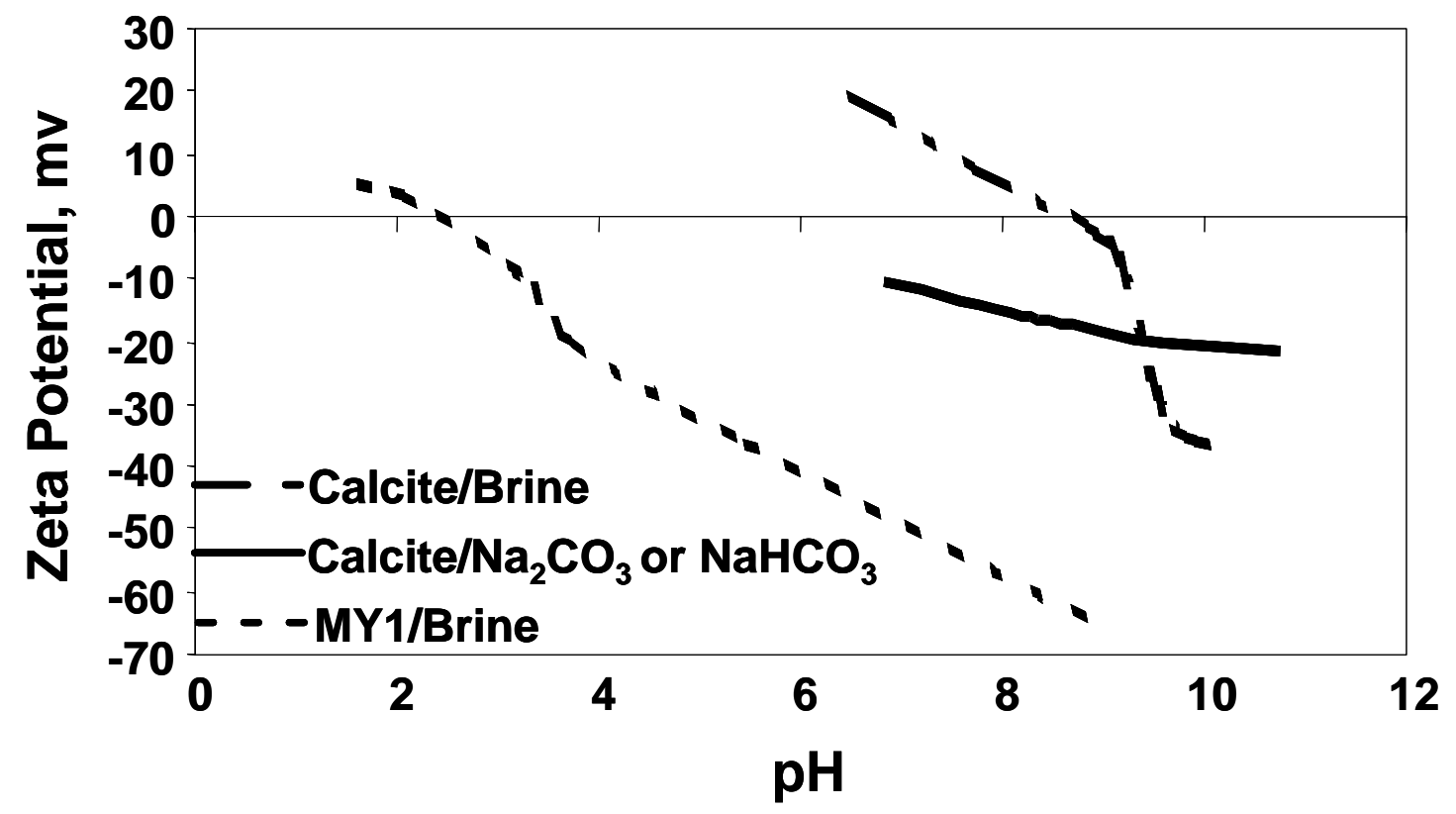

Fig. 7 Zeta potential of MY1 crude oil/brine and calcite/brine interfaces in $0.02 \mathrm{M} \mathrm{NaCl}$ as a function of $\mathrm{pH}$ without and with added $\mathrm{Na}_{2} \mathrm{CO}_{3} / \mathrm{NaHCO}_{3}$ and $\mathrm{pH}$ adjusted with $\mathrm{HCl}$. 
- Large contact angle on marble in $0.1 \mathrm{M} \mathrm{NaCl}$ $1 \mathrm{~mm}$

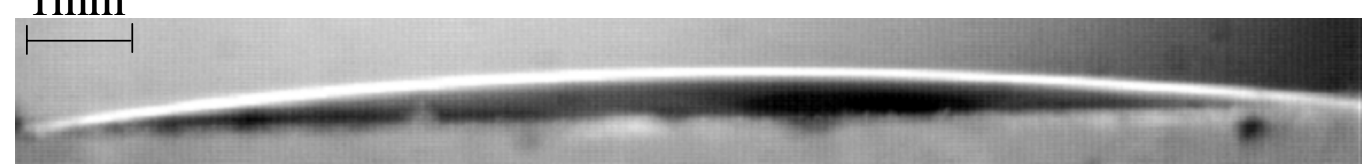

(a)

- Effect of $0.05 \%$ CS-330/0.5M Na $\mathrm{NO}_{3}$

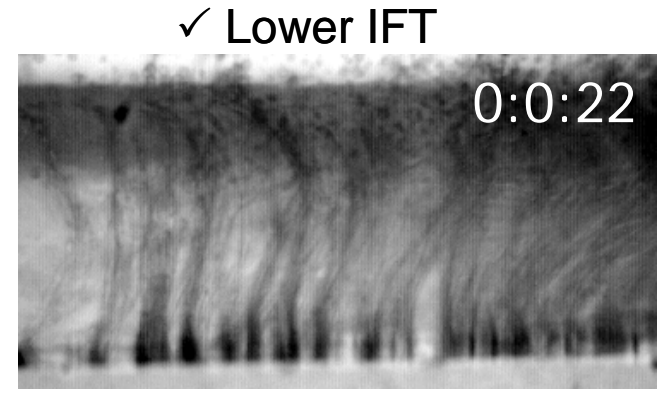

(b)

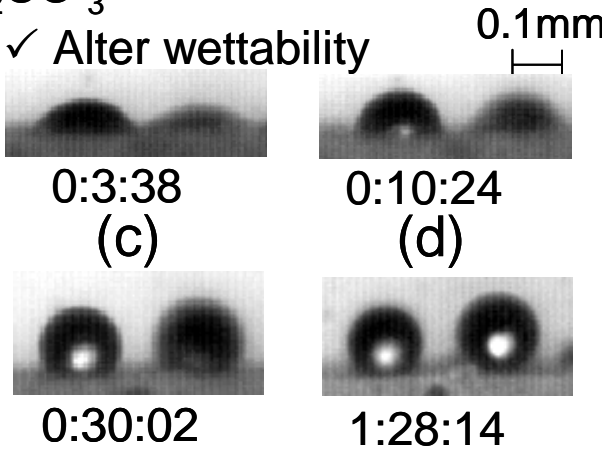

(e)

(f)

(Time: [hours: minutes: seconds])

Fig. 8 Wettability alteration of calcite plate aged at room temperature with $0.05 \% \mathrm{CS}-330 / 0.5 \mathrm{M} \mathrm{Na}_{2} \mathrm{CO}_{3}$.

- Large contact angle on marble in $0.1 \mathrm{M} \mathrm{NaCl}$

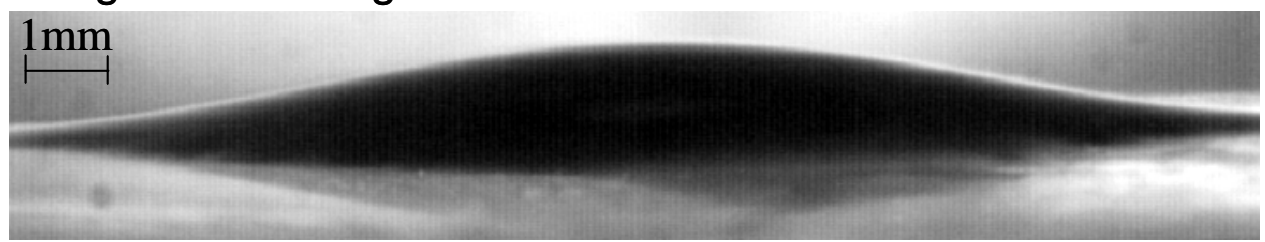

(a)

- Effect of $0.05 \%$ CS-330/0.5M Na $\mathrm{CO}_{3}$

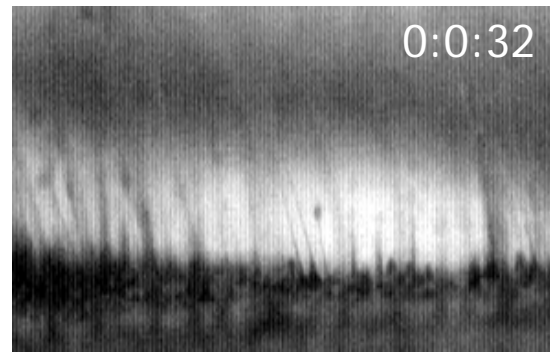

(b)

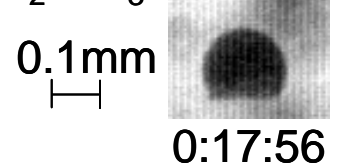

(c)

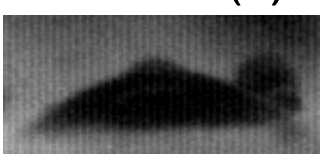

4:06:44

(e)

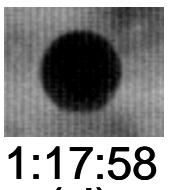

(d)

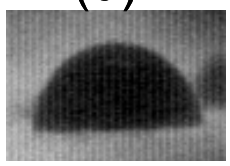

$22: 48: 38$

(f)

(Time: [hours: minutes: seconds])

Fig. 9 Wettability alteration of calcite plate aged at $80^{\circ} \mathrm{C}$ with $0.05 \% \mathrm{CS}-330 / 0.5 \mathrm{M} \mathrm{Na}_{2} \mathrm{CO}_{3}$. (Two different drops show different wettability.) 


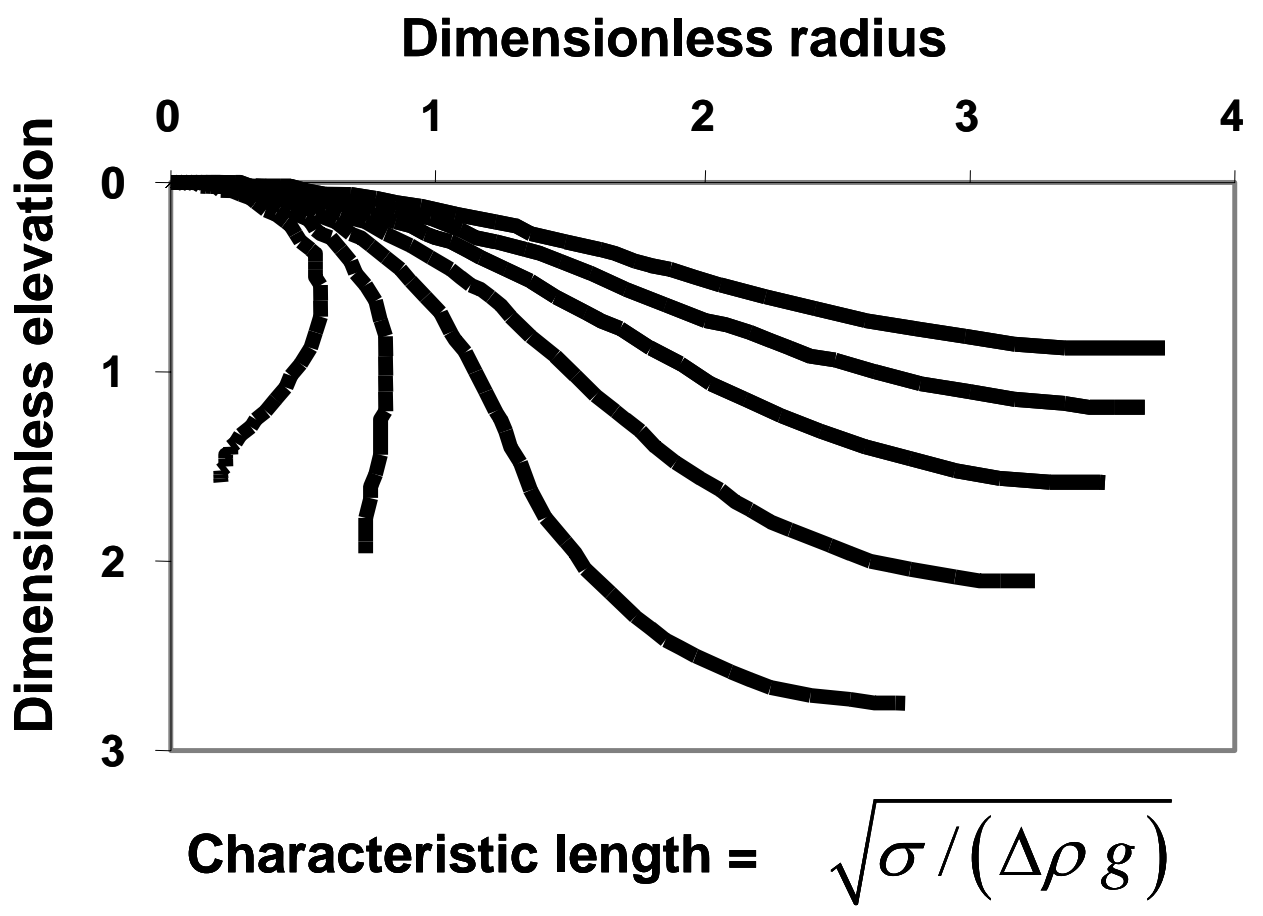

Fig. 10 Family of axisymmetric oil interfaces for an oil drop immersed in water. Each curve has a different curvature at the apex of the drop. The distances are normalized by $\sqrt{\sigma /(\Delta \rho g)}$.

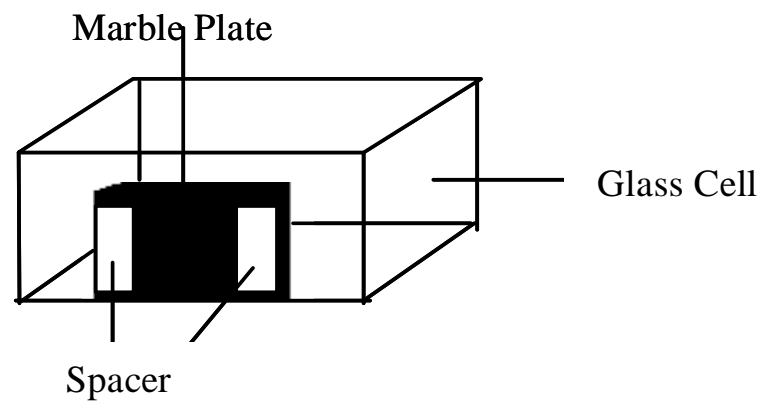

Front View

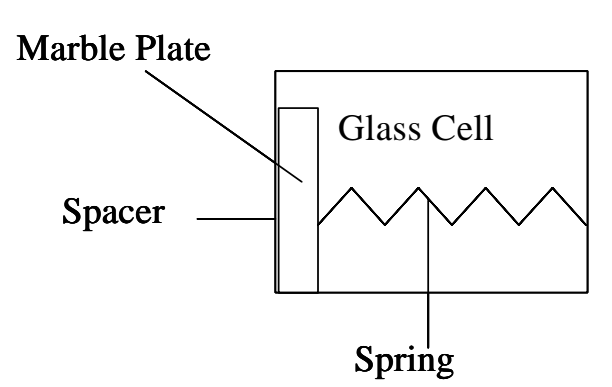

Side View

Fig. 11 A calcite (marble) plate has two plastic films to create a $13 \mu \mathrm{m}$ gap between the plate and the front of an optical cell. 


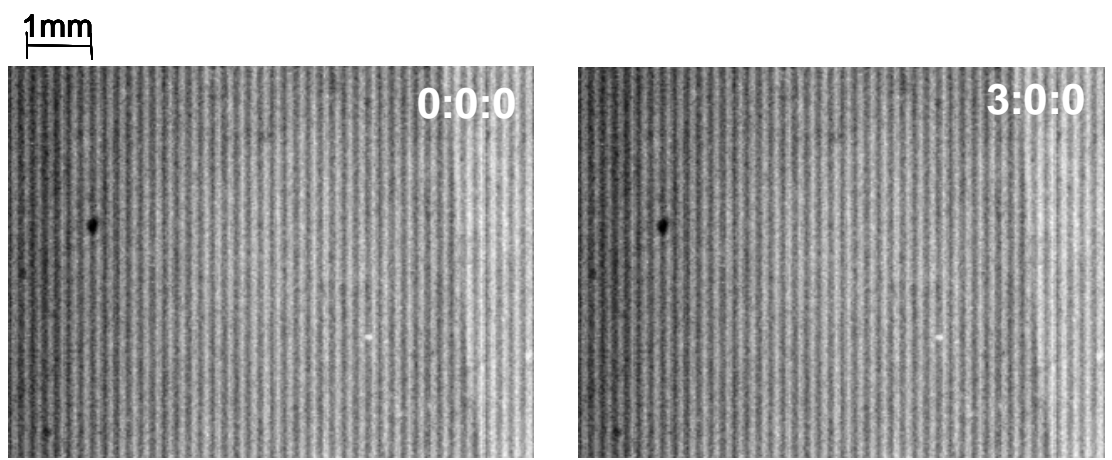

(a)
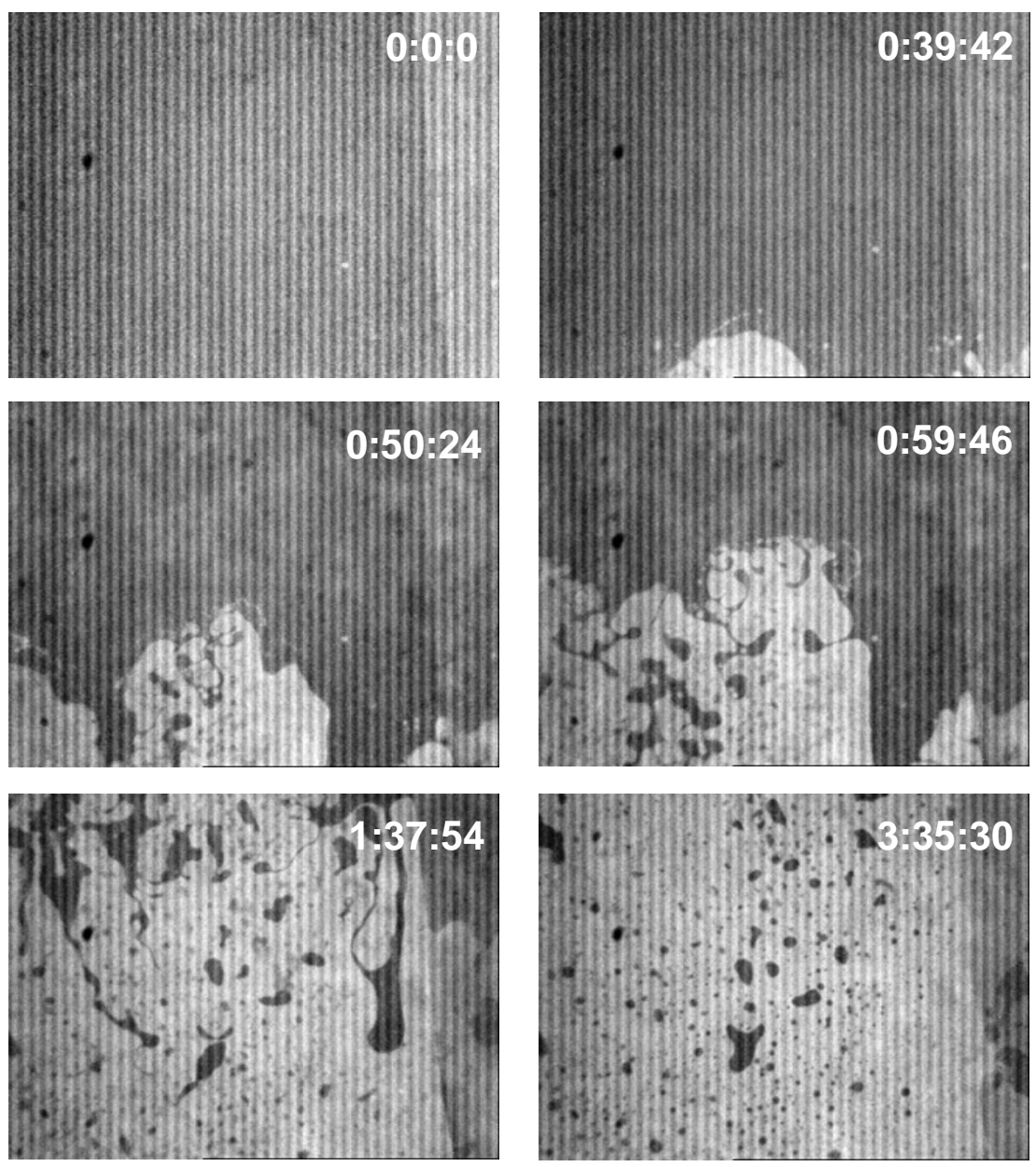

(b)

Fig. 12 Displacement of crude oil in narrow gap with (a) brine or with (b) alkaline surfactant solution. 


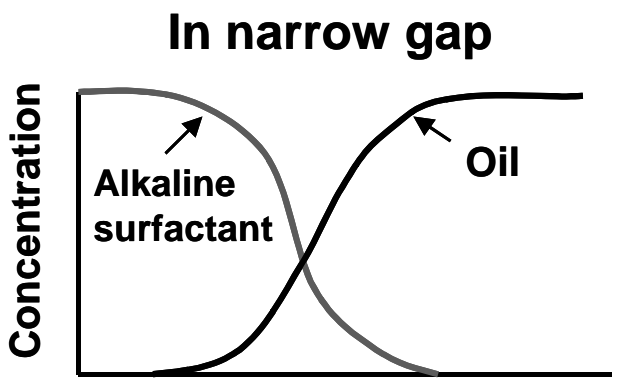

Distance
In porous rock

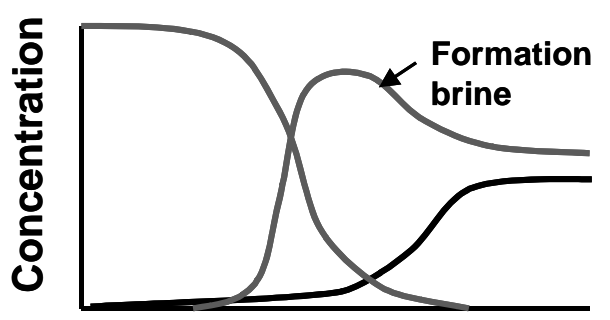

Distance

Fig. 13 Saturation/concentration profiles in a narrow gap or in a porous rock during displacement of oil by buoyancy.

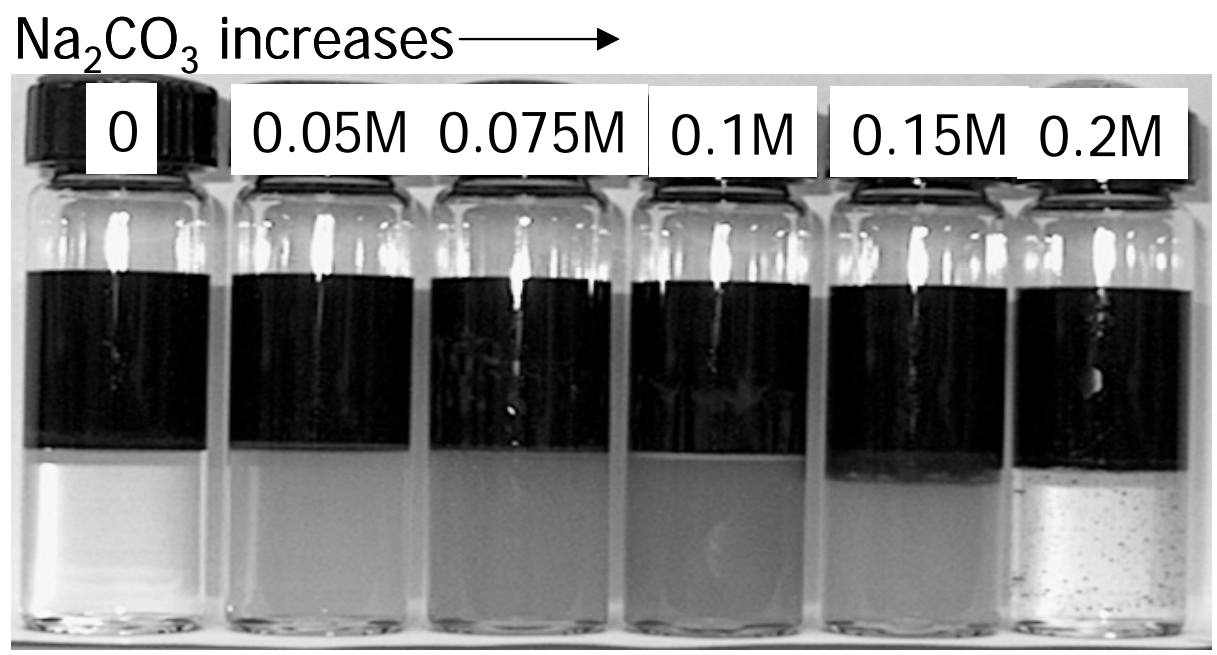

Fig. 14 Phase behavior of MY3 crude oil and different concentrations of $\mathrm{Na}_{2} \mathrm{CO}_{3}$. 
$0.05 \% \mathrm{CS}-330, \mathrm{WOR}=1, \mathrm{Na}_{2} \mathrm{CO}_{3}$ increases $\longrightarrow$

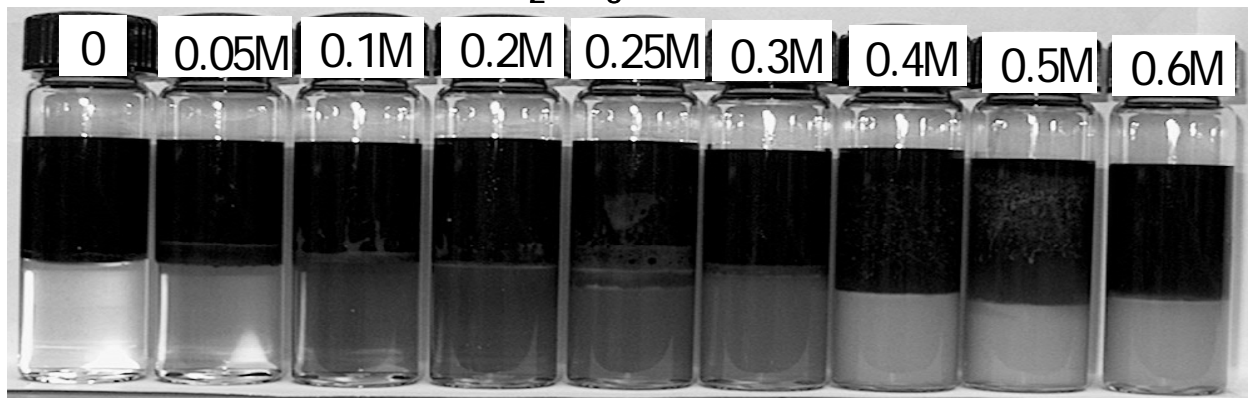

$0.05 \% \mathrm{CS}-330 / 0.5 \mathrm{M} \mathrm{Na}_{2} \mathrm{CO}_{3}$, WOR increases

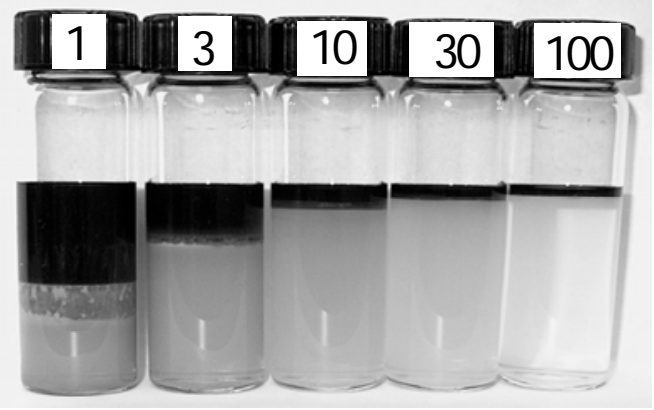

Fig. 15 Phase behavior of MY3 crude oil with $0.05 \%$ (AM) CS-330.

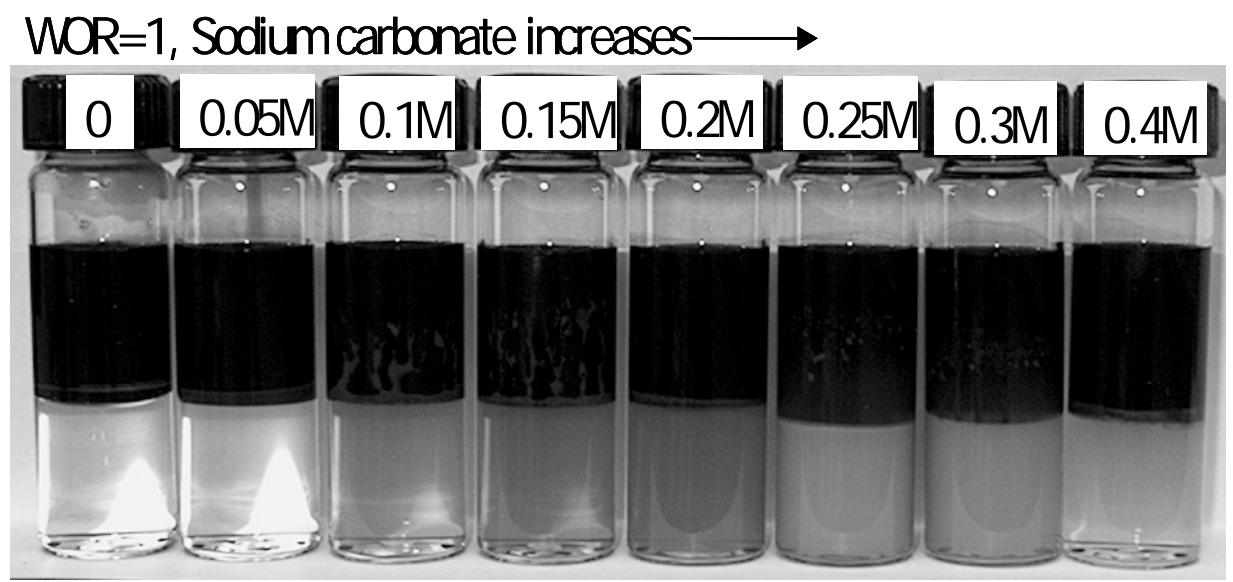

$0.2 \mathrm{M} \mathrm{Na}_{2} \mathrm{CO}_{3}$, WOR increases

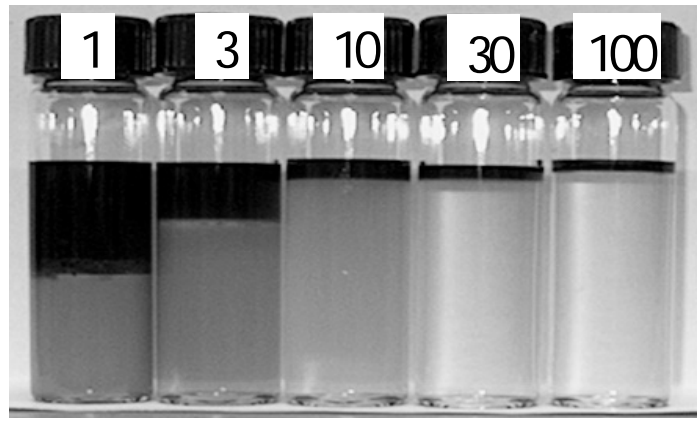

Fig. 16 Phase behavior of MY3 crude oil with 0.05\% (AM) C12-3PO. 
WOR $=1$, Sodium carbonate increases

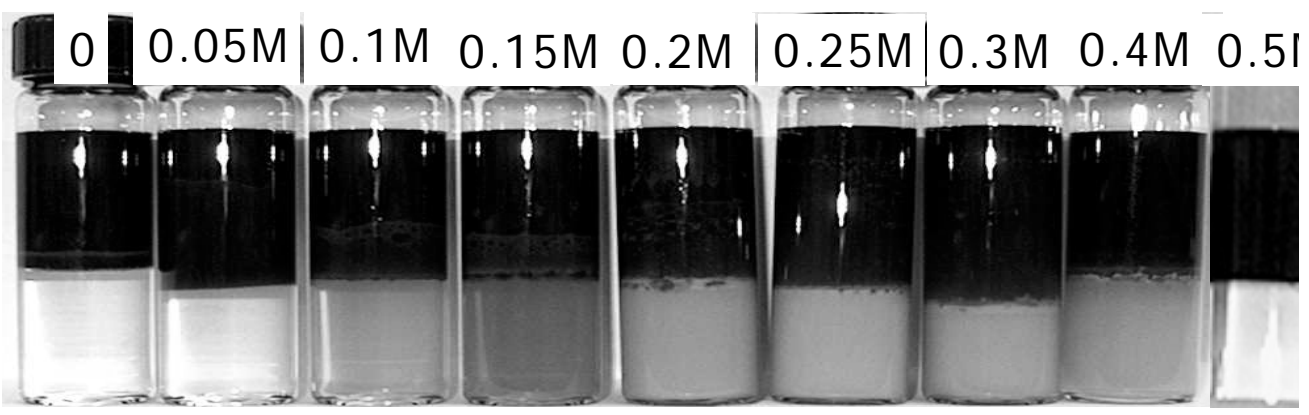

$0.3 \mathrm{M} \mathrm{Na}_{2} \mathrm{CO}_{3}$, WOR increases $\longrightarrow$

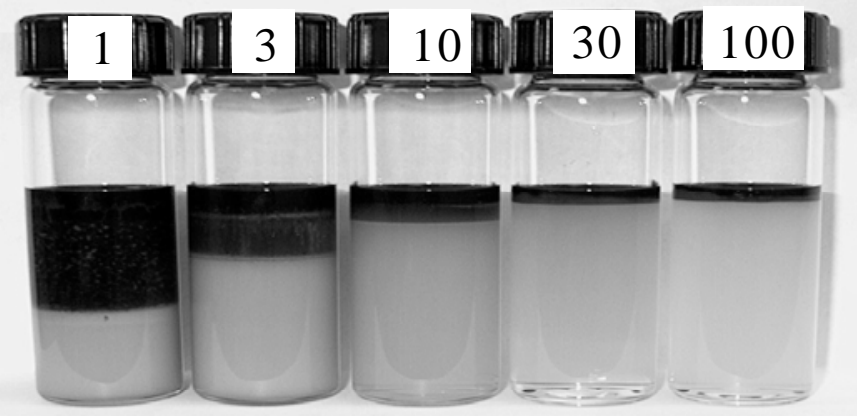

Fig. 17 Phase behavior of MY3 crude oil with $0.05 \%$ (AM) TDA-4PO.

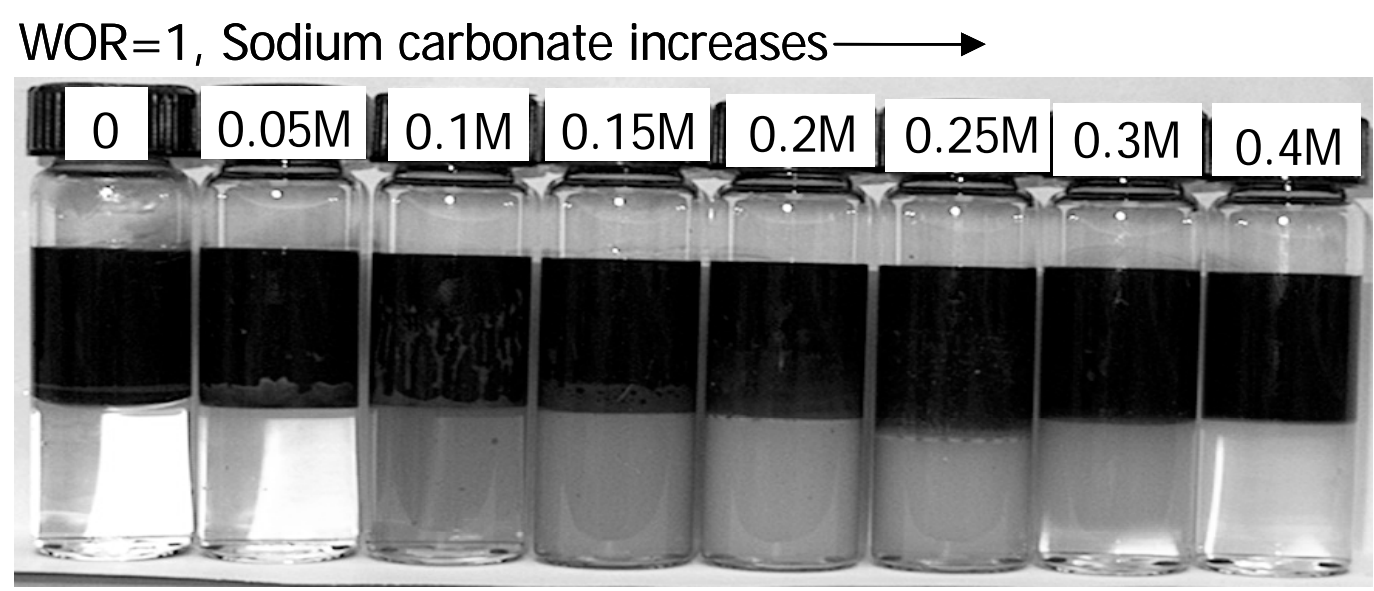

$0.2 \mathrm{M} \mathrm{Na}_{2} \mathrm{CO}_{3}$, WOR increases $\longrightarrow$

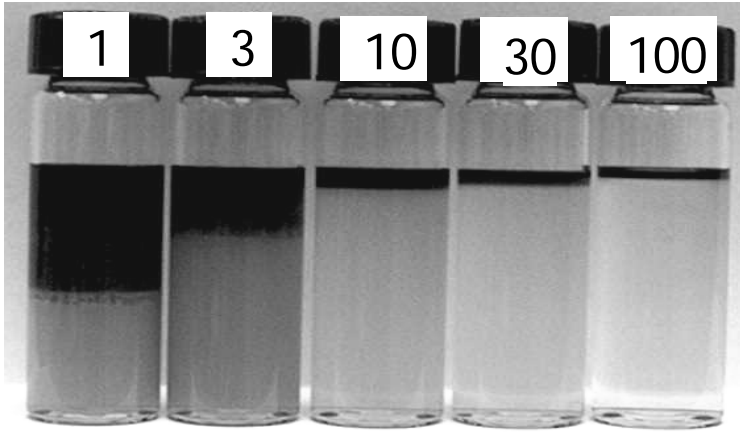

Fig. 18 Phase behavior of MY3 crude oil with $0.05 \%$ (AM) ISOFOL 14T-4.1PO. 


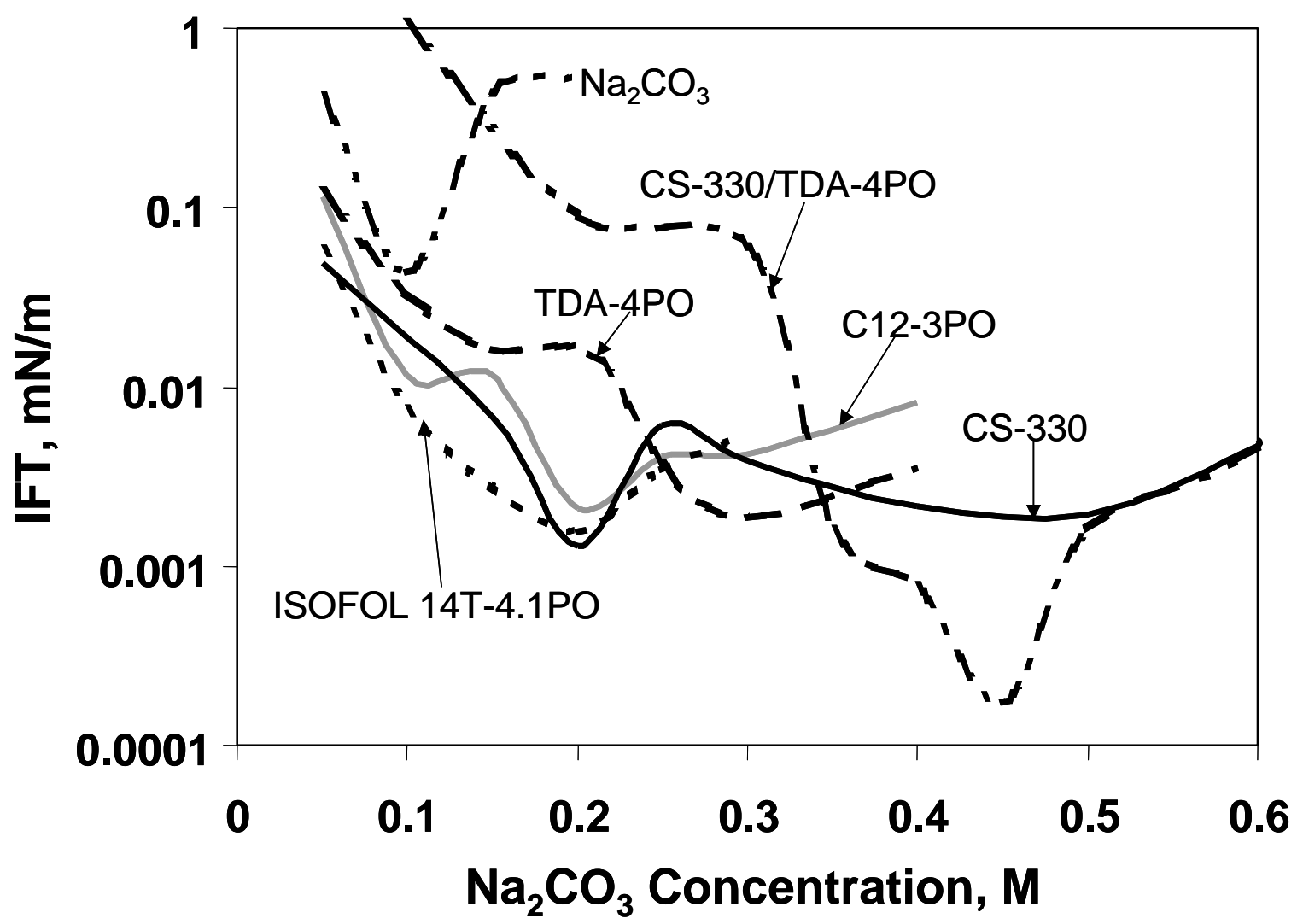

Fig. 19 IFT of MY3 crude oil with $0.05 \%$ (AM) surfactant solution as a function of $\mathrm{Na}_{2} \mathrm{CO}_{3}$ concentration. Water/Oil ratio $=1: 1$

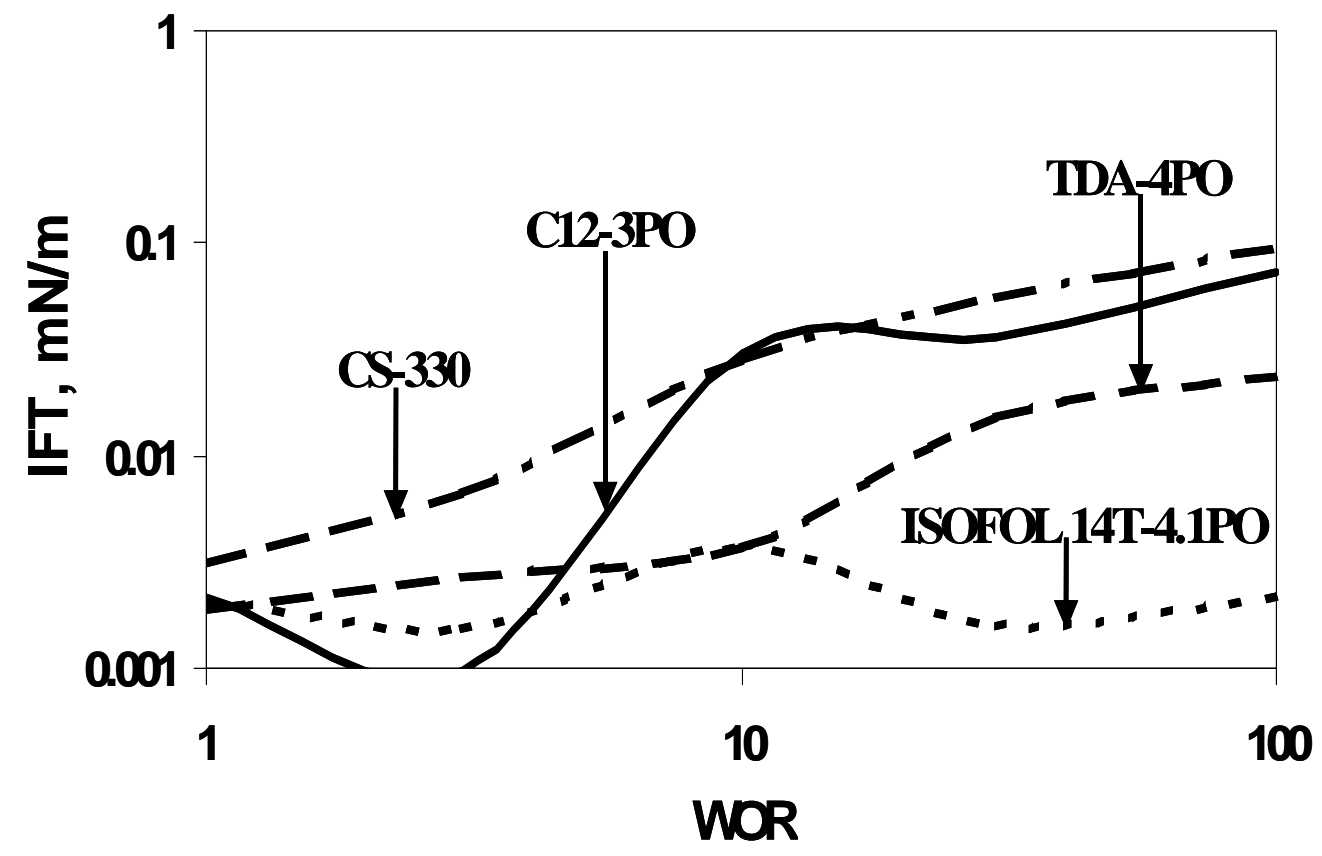

Fig. 20 IFT of MY3 crude oil with $0.05 \%$ (AM) surfactant solution as a function of water/oil ratio. WOR=1 is close to the optimal $\mathrm{Na}_{2} \mathrm{CO}_{3}$ concentration. 

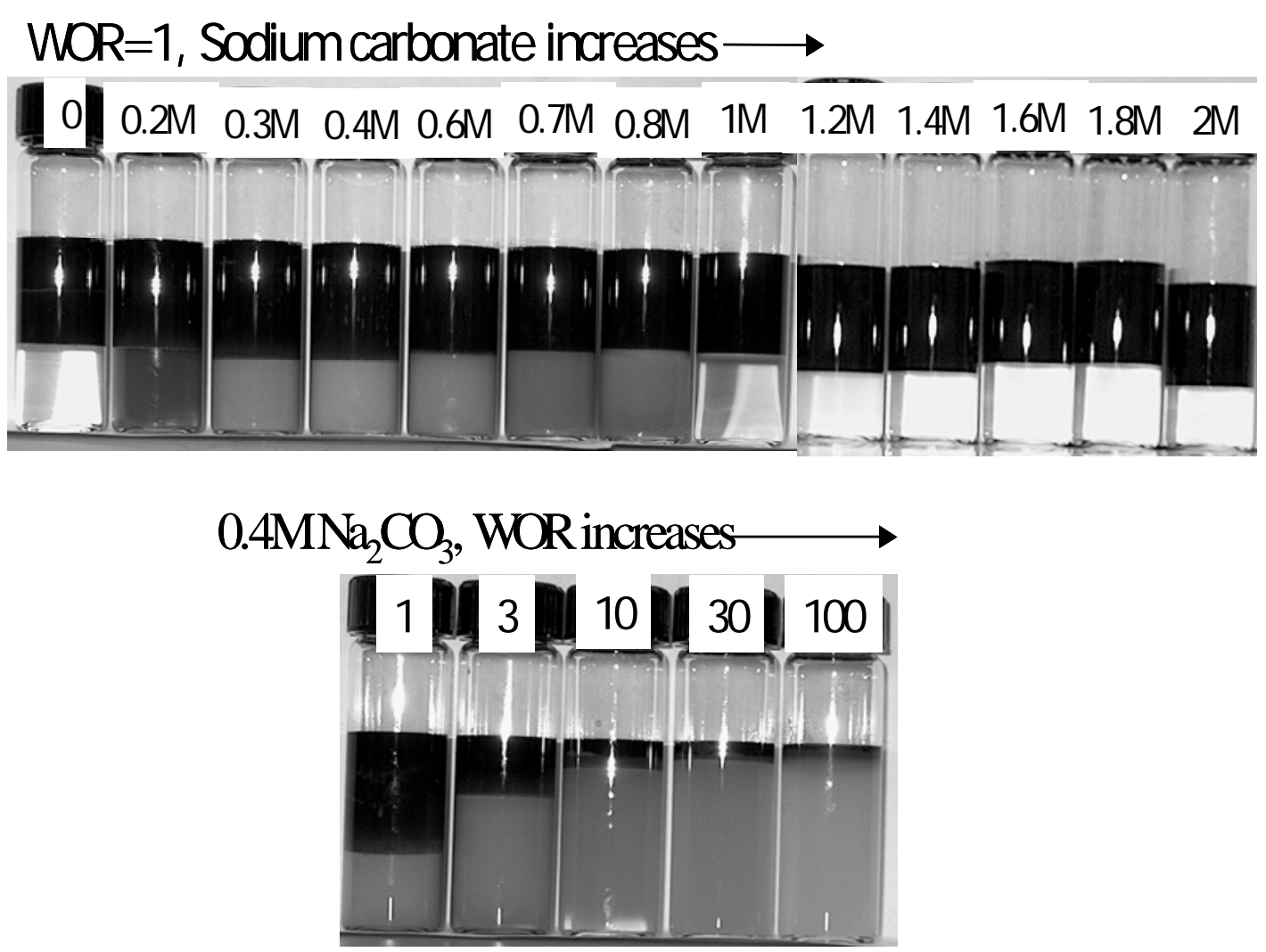

Fig. 21 Phase behavior of MY3 crude oil with $0.2 \%$ (AM) TDA-4PO.
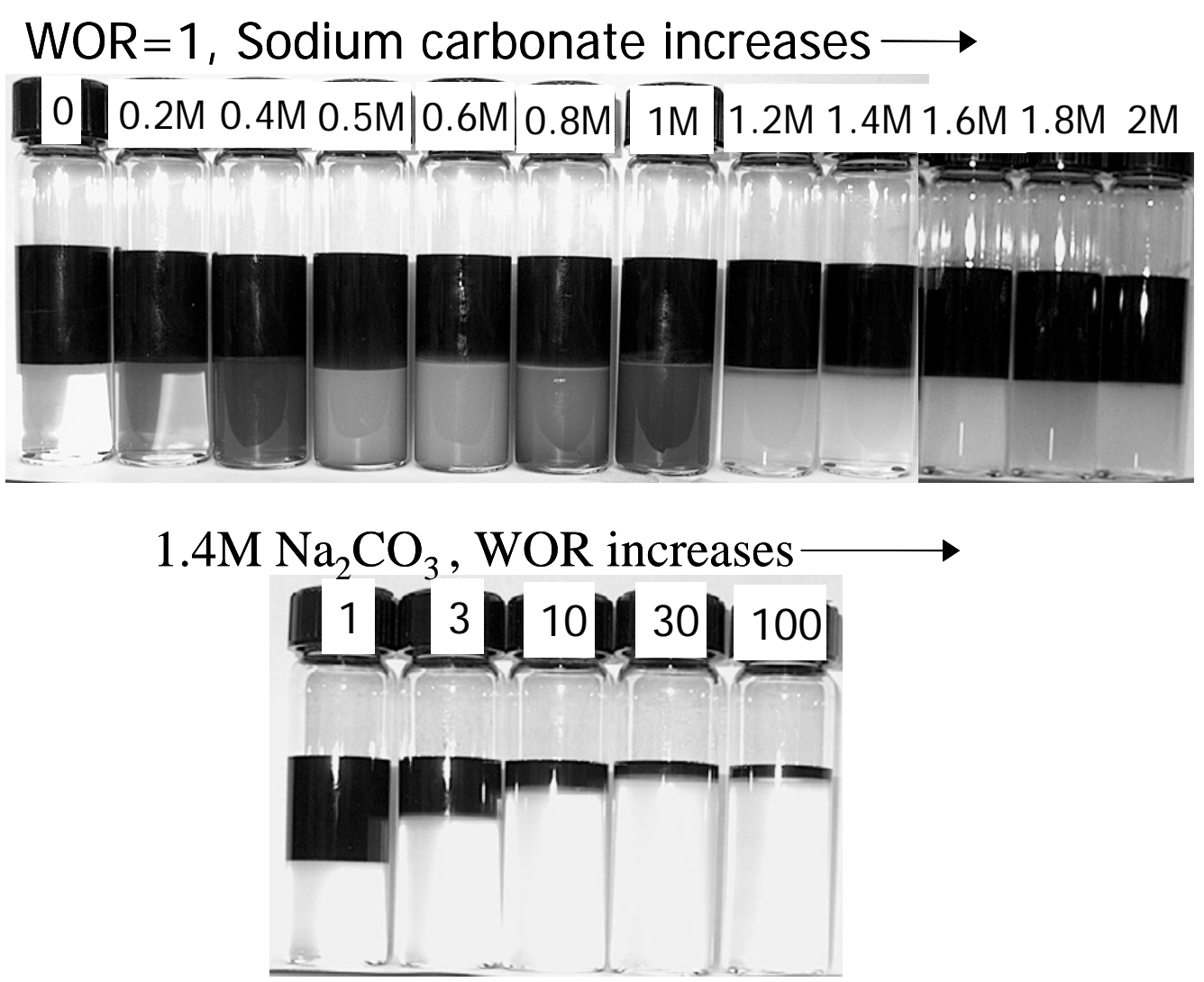

Fig. 22 Phase behavior of MY3 crude oil with 1\% (AM) TDA-4PO. 


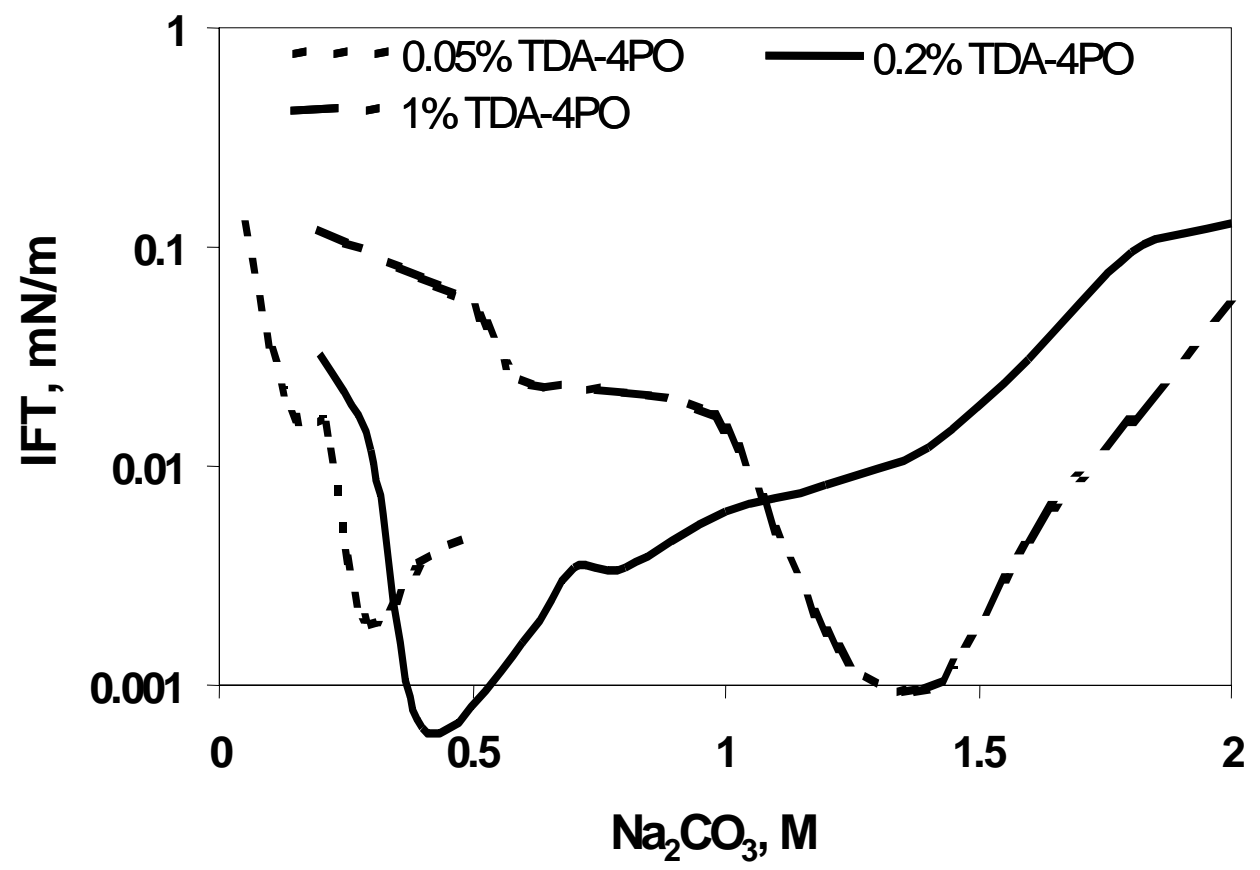

Fig. 23 IFT of MY3 crude oil with $0.05 \%, 0.2 \%$, and $1 \%$ (AM) TDA-4PO as a function of $\mathrm{Na}_{2} \mathrm{CO}_{3}$ concentration. Water/oil ratio $=1: 1$.
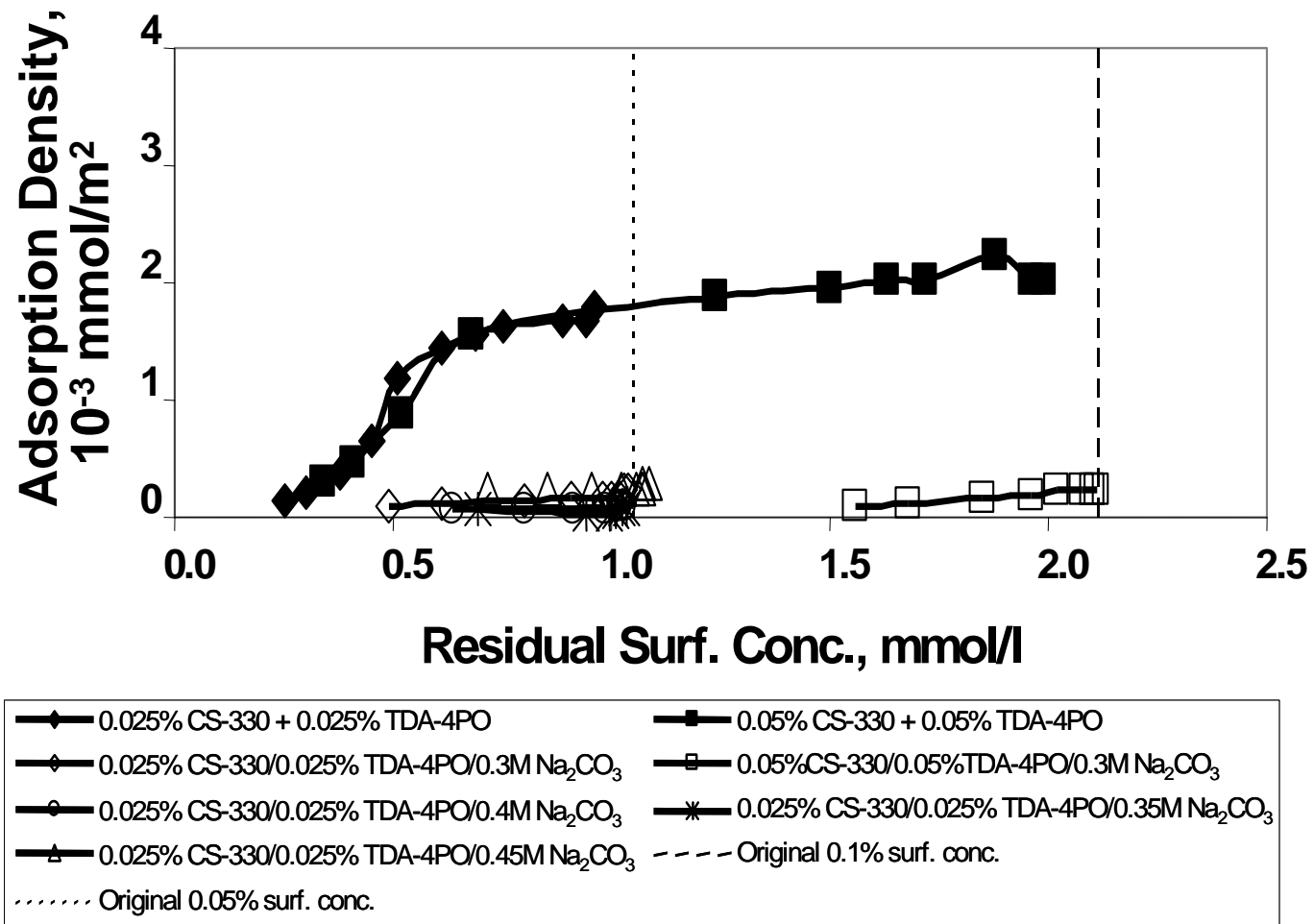

Fig. 24 Adsorption isotherms of CS-330 + TDA-4PO without and with sodium carbonate. 


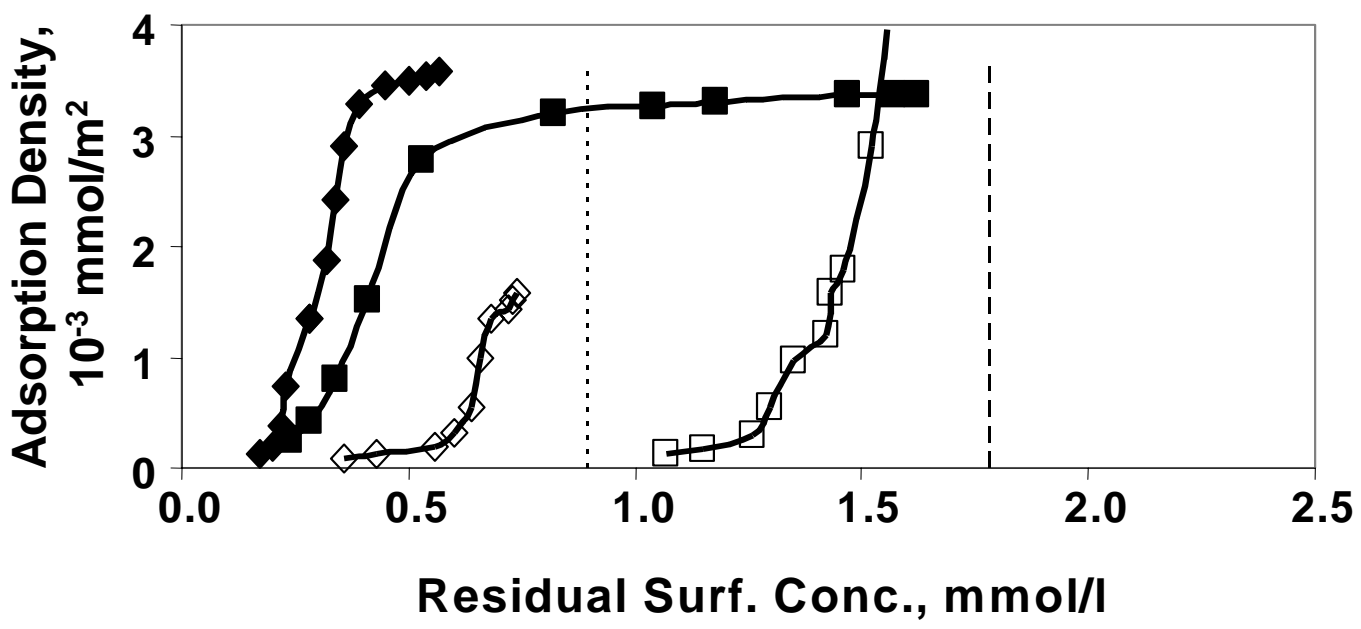

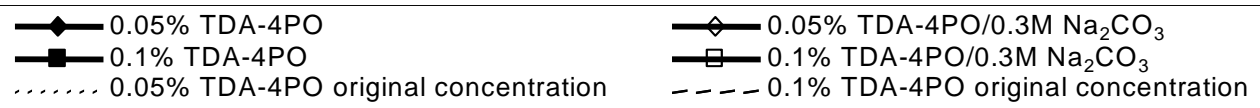

Fig. 25 Adsorption isotherms of TDA-4PO without and with sodium carbonate.

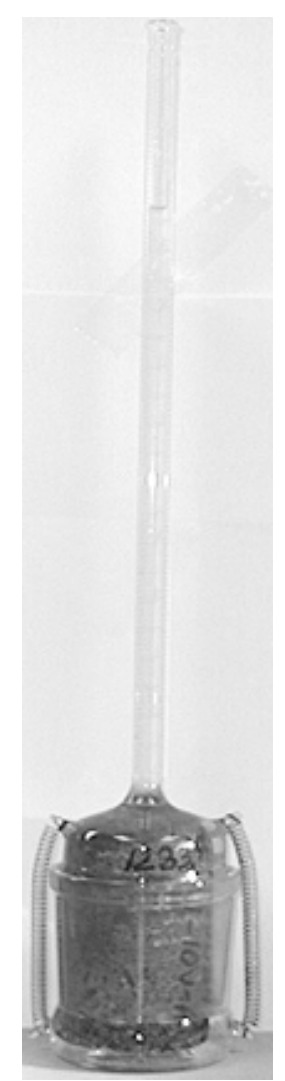

(a)

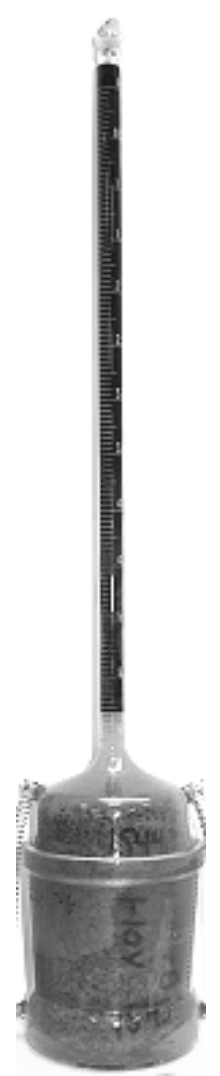

(b)

Fig. 26 Spontaneous imbibition with (a) brine, or (b) alkaline surfactant solution. 


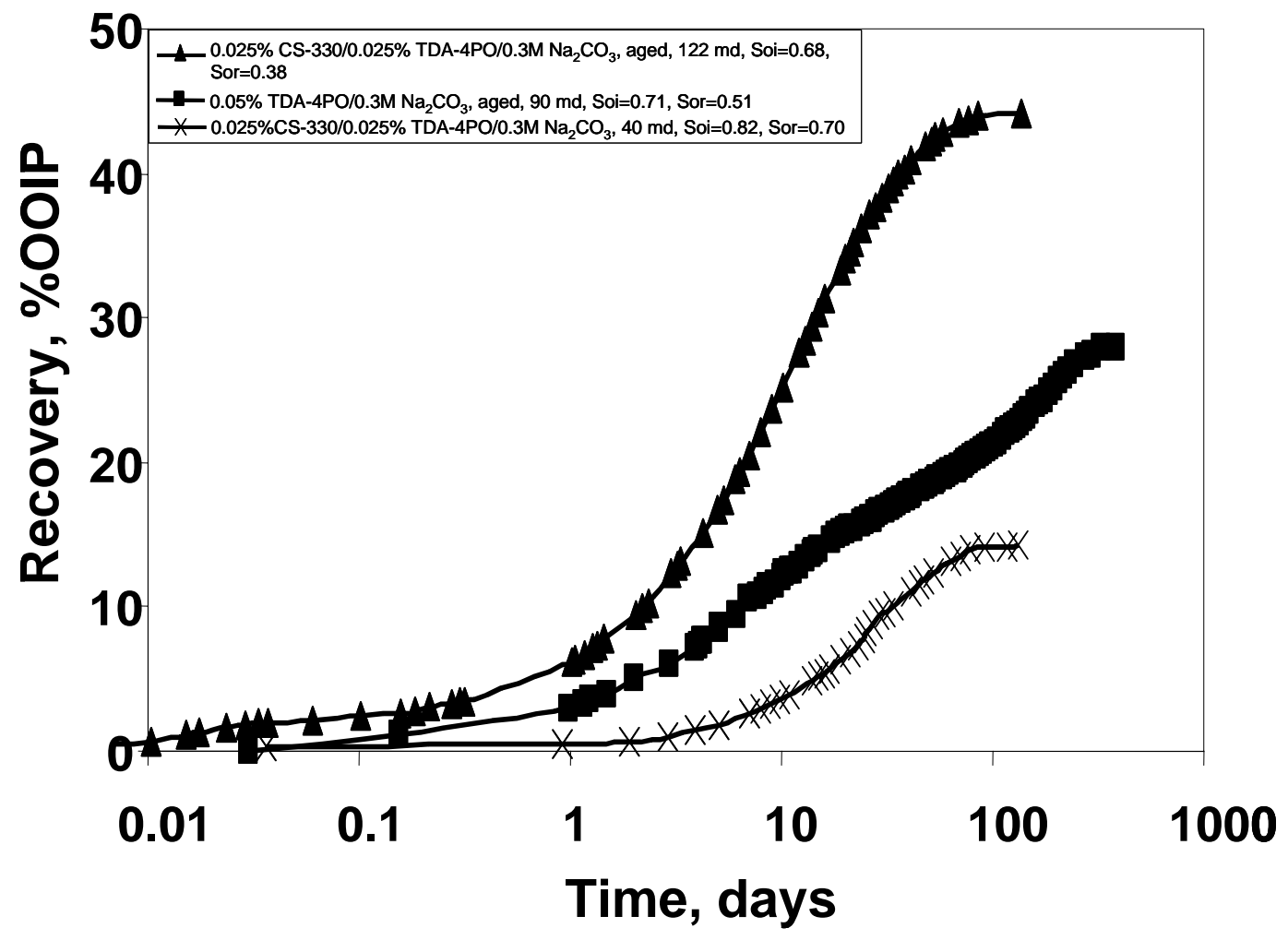

Fig. 27 Oil recovery by spontaneous imbibition.

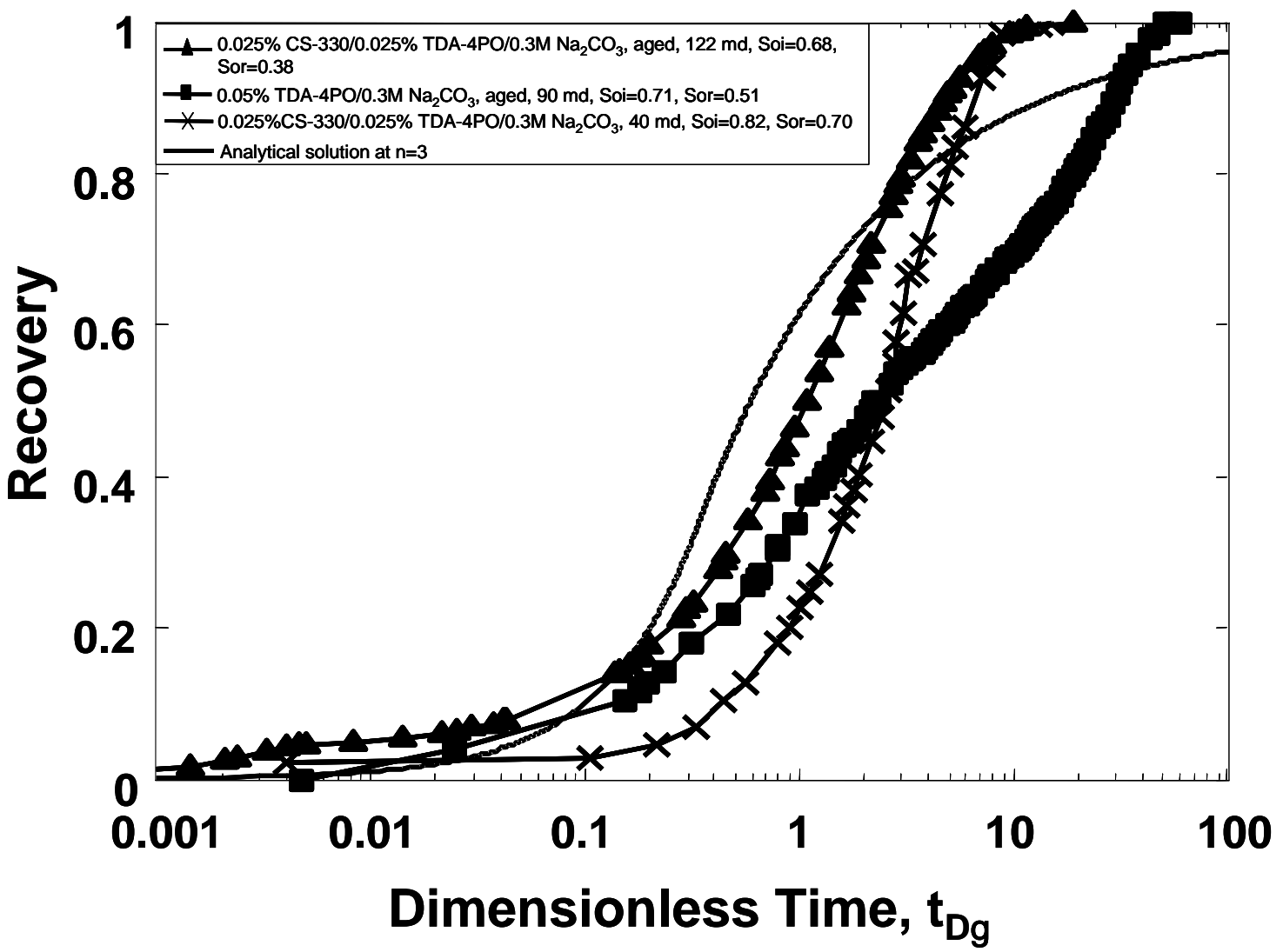

Fig. 28 Oil recovery by spontaneous imbibition as function of dimensionless time for gravity drainage. 


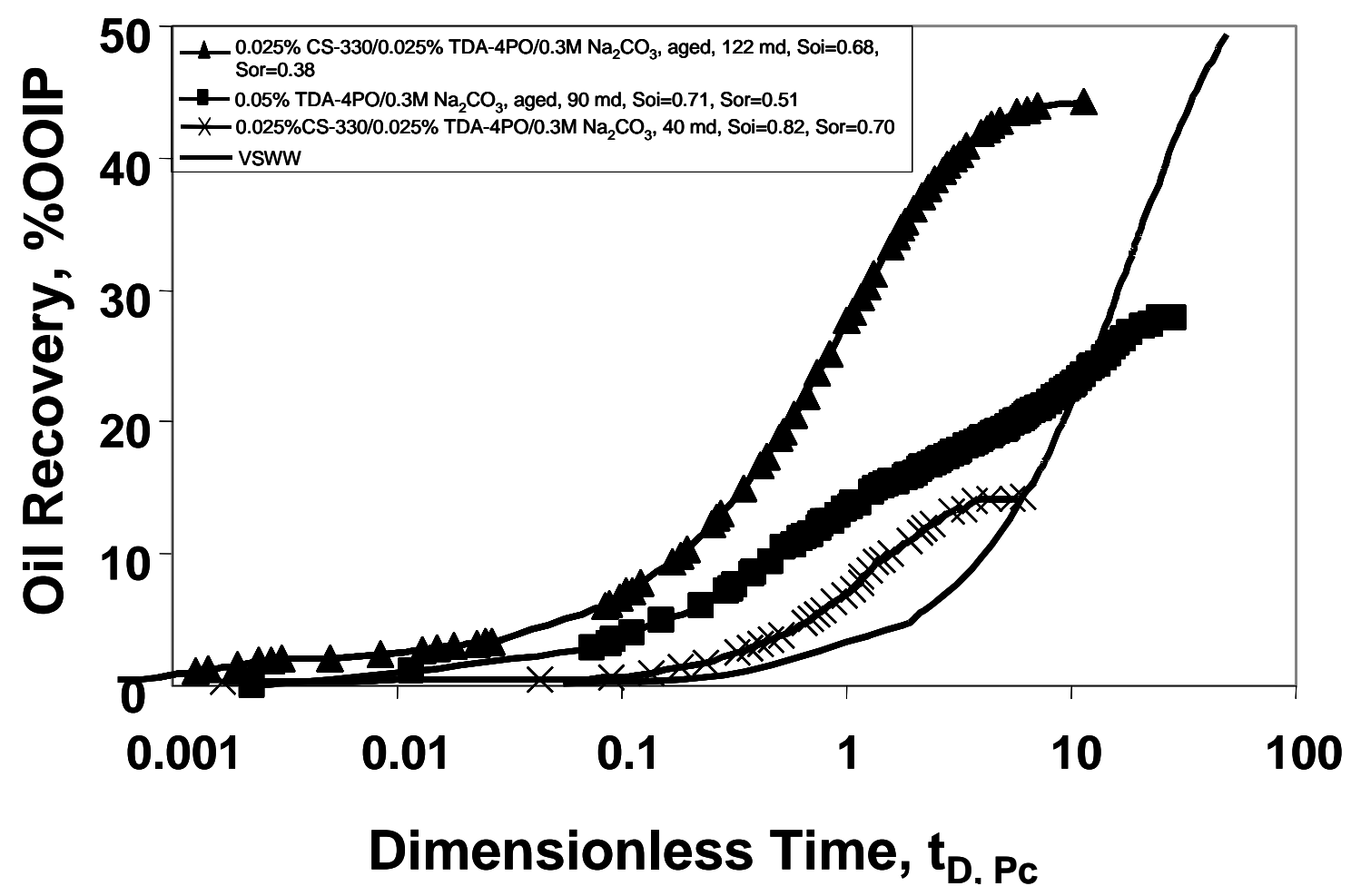

Fig. 29 Oil recovery by spontaneous imbibition as function of dimensionless time for capillary imbibition, assuming IFT of $10^{-3} \mathrm{mN} / \mathrm{m}$ 